\title{
Nanocomposite scaffolds for accelerating chronic wound healing by enhancing angiogenesis
}

\author{
Hamed Nosrati ${ }^{*} \mathbb{B}$, Reza Aramideh Khouy ${ }^{2}$, Ali Nosrati ${ }^{3}$, Mohammad Khodaei $^{4}$, Mehdi Banitalebi-Dehkordi ${ }^{5}$, \\ Korosh Ashrafi-Dehkordi ${ }^{5}$, Samira Sanami ${ }^{6}$ and Zohreh Alizadeh ${ }^{7,8}$
}

\begin{abstract}
Skin is the body's first barrier against external pathogens that maintains the homeostasis of the body. Any serious damage to the skin could have an impact on human health and quality of life. Tissue engineering aims to improve the quality of damaged tissue regeneration. One of the most effective treatments for skin tissue regeneration is to improve angiogenesis during the healing period. Over the last decade, there has been an impressive growth of new potential applications for nanobiomaterials in tissue engineering. Various approaches have been developed to improve the rate and quality of the healing process using angiogenic nanomaterials. In this review, we focused on molecular mechanisms and key factors in angiogenesis, the role of nanobiomaterials in angiogenesis, and scaffoldbased tissue engineering approaches for accelerated wound healing based on improved angiogenesis.
\end{abstract}

Keywords: Scaffold, Angiogenesis, Chronic wound, Wound healing, Skin tissue engineering, Nanobiotechnology

\section{Background}

Wound healing is an accurate and well-orchestrated process in healthy individuals. Nevertheless, shortcomings in the wound healing lead to more than 38 million patients with chronic wounds worldwide, reaching epidemic proportions, causing a huge economic burden on the healthcare systems $[1,2]$. It has actually been described that chronic wounds can have as profound an impact on the quality of life as renal and cardiovascular disorders. In addition, mortality nowadays rivals that of cancer patients for some patients with chronic wounds [3]. Autoimmune diseases, diabetes, aging, cardiovascular diseases, obesity, sensory neuropathies or constitute some of the reasons that cause the aforementioned pathology [4]. According to the latest Global Wound Care

\footnotetext{
*Correspondence: hamednosratibio@gmail.com

${ }^{1}$ Department of Tissue Engineering and Applied Cell Sciences, School of Advanced Technologies, Shahrekord University of Medical Sciences, Shahrekord, Iran

Full list of author information is available at the end of the article
}

Market report, the sector has reached a value of about 20 billion dollars. Moreover, this amount is estimated to reach more than 25 billion dollars worldwide in 2023 [5]. It is therefore reasonable that adequate and well-planned management of chronic wounds has become important over the last decades in order to improve human quality of life and increase life expectancy.

In recent decades, various strategies have been developed for the treatment of chronic wounds. The most successful clinical strategy is skin autograft. Lack of immunogenicity is the most significant advantage of this method, but when the injured area exceeds more than $60 \%$ of the patient's total body surface area, autografts could not cover the entire wounded site [6]. Pain, pigmentation disturbance and hair regeneration problems are other reported post-surgical issues related to the donor site [7]. Due to the limitations of this method, alternative strategies need to be developed to accelerate the process of wound healing. In order to develop novel approaches, a comprehensive understanding of the 
process of chronic wound healing and the mechanisms of the most important factors affecting the process are needed.

Wound healing is a complex multi-step process. In the first step, a clot plugs the wounded site. The repair and regeneration of the area would then continue with the formation of granulation tissue due to the introduction of fibroblasts, capillaries and immune cells into the clot. The edge of the wound would be aggregated and the epidermal layer would cover the surface of the wound. A balance between cell activity, such as proliferation, migration, differentiation and apoptosis, would lead to the creation of multilayer skin [8-10]. In this process, angiogenesis plays a significant role in improving the rate and quality of the healing process, and therefore the key role of angiogenesis is central to many studies of wound healing. In brief, angiogenesis implies the formation of new capillaries from pre-existing vessels to create a complex network of blood vessels [11]. Angiogenesis at the wound site provides more nutrition through blood flow and improves the healing process.

Many strategies to improve skin regeneration are based on stimulating and enhancing angiogenesis. In this regard, a promising approach is to use engineered structures, such as scaffolds with or without cells that can mimic the native tissue functionally. Such scaffolds could provide an appropriate microstructure similar to the extracellular matrix (ECM) for native cells to proliferate, migrate and differentiate. Various elements and factors, such as ions, nanoparticles and growth factors, could be incorporated in these structures to give them angiogenic properties. As an example, nanoparticles that are currently used as drug carriers could be incorporated into nanofibrous scaffolds that could provide a high surface/ volume ratio for cell adhesion. The attached cells would be exposed to the angiogenic factors [12-15]. The use of nanocomposite scaffolds to improve angiogenesis in the field of skin tissue engineering has significantly increased over the last decade [16]. In this paper, we will discuss molecular mechanisms and key factors in angiogenesis, the role of nanobiomaterials in angiogenesis, and scaffold-based tissue engineering approaches for accelerated wound healing based on improved angiogenesis.

\section{Angiogenesis in wound healing}

Immediately after the accumulation of inflammatory cells following the injury, many angiogenic agents are secreted by these cells, causing the formation of new blood vessels. Defects in angiogenesis at this stage may lead to chronic wounds due to a slow rate of healing $[11,17]$. After the inflammatory response following the injury, signals are transmitted to the endothelial cells that stimulate these cells to secrete matrix metalloproteinases (MMPs) and some other proteases leading to degradation of the basement membrane [18]. This situation provides an opportunity for the invasion of the tip cells into the surrounding matrix. The tip cells develop from the endothelial cells through the notch signaling pathway and are responsible for invasion and germination [19]. Proliferative stem cells are originated from other endothelial cells in order to develop vascular lumen. At last, the adherence of endothelial cells, with the help of vascular endothelial cadherin (VE-cadherin) as the main adhesive molecules, inhibits the proliferation to finalize vascularization [20]. Pericytes surrounded by basement membranes help to stabilize the recently formed vessels [21]. Figure 1 shows the main stages of angiogenesis process.

\section{Main factors of angiogenesis}

\section{Vascular endothelial growth factor (VEGF)}

Many studies have demonstrated that the VEGF family is the most important stimulating factor in the angiogenesis process. The main role of VEGF is to stabilize the vascular system through the formation of new networks of blood vessels. VEGF also involves the development of embryonic vascular system [25]. VEGF-A is the main stimulator of the blood vessels growth. VEGF-A is responsible for VEGFR2 phosphorylation, which induces endothelial cell migration, proliferation and differentiation [26]. Growth factors, cytokines, hypoxia and hormones are the most important regulatory factors for $V E G F-A$ gene expression [27]. VEGFR1, VEGFR2 and VEGFR3 are the tyrosine kinase receptors of the VEGF family. VEGF-A, VEGF-B and PGF are related to VEGFR1. VEGF-A also has an affinity to VEGFR2. The primary receptor for VEGF-C and VEGF-D is VEGFR3 [28].

VEGFR1 is structurally the same as VEGFR2. VEGFR1 is responsible for the negative regulation of VEGFR2 activities. VEGFR1 could transmit angiogenesis regulation signals by phosphorylation of downstream protein through an auto-phosphorylation process $[29,30]$. VEGFR2 has a stronger tyrosine activity compared to VEGFR1, which can promote the survival, proliferation and migration of endothelial cells in order to improve angiogenesis [29]. One of the most important signaling pathways leading to endothelial cell proliferation is $\mathrm{PLC} / \mathrm{PKC} / \mathrm{MAPK}$, which is induced by the binding of VEGF to VEGFR2 [31]. A summary of the signaling pathways induced by three types of VEGF receptors binding to their ligands is shown in Fig. 2.

\section{Angiopoietin}

Angiopoietin (ANGPT) plays a central role in the process of angiogenesis. It also regulates the permeability of vessels, causes vascular maturation, and keeps integrity and stability of the blood vessels. Survival 
a

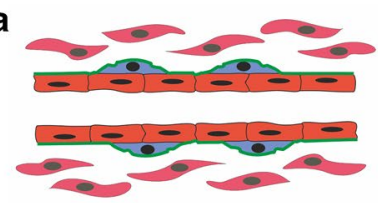

c

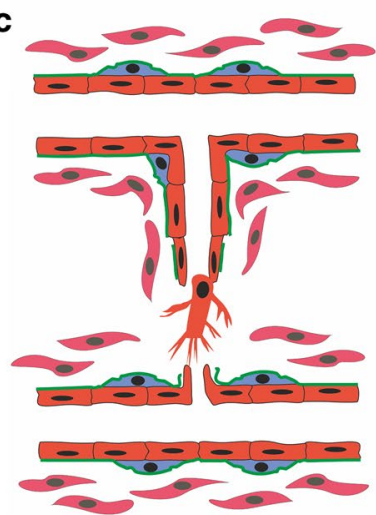

b

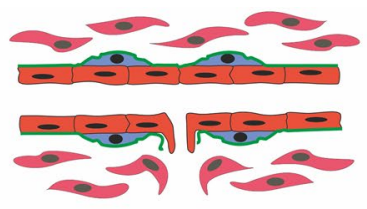

d

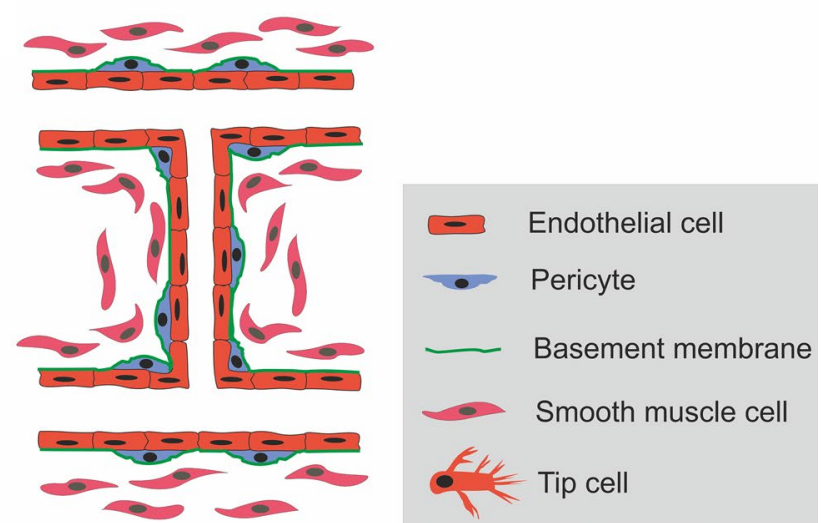

Fig. 1 Main stages of angiogenesis [22-24]. A normal blood vessel (a). Angiogenic substances stimulate the angiogenesis process (b). Invasion of tip cells and lumen formation (c). Maturation of the new formed blood vessel (d)

and proliferation of endothelial cells and pericytes are affected by levels of ANGPT [41]. Receptors of ANGPT, Tie1 and Tie2, were identified in 1992. Tie2 is the receptor for ANGPT ligands and researchers have recently demonstrated the regulatory effects of Tie1 on Tie2 tyrosine kinase activity [42]. ANGPT-1 and ANGPT-2 were identified after the identification of their receptors. ANGPT-3 and ANGPT-4 were cloned from rodent and human sources, respectively [43]. Cells around the blood vessels are the primary source of ANGPT-1 expression. When ANGPT-1 is bound to its receptor (Tie2), the tyrosine kinase pathway is activated, leading to dimerization of the receptor by which tyrosine residues are phosphorylated. Cell viability, attachment, proliferation, migration and improved vessel stability are the results of studies obtained by activation of Akt and protein kinase B through the P13K signaling pathway $[44,45]$. Yuan et al. showed the partial agonist/antagonist function of ANGPT-2 in Tie2 signaling in endothelium. ANGPT-2 also plays a key role in the regulation of angiogenesis by activating Tie2. In endothelial cells, the secretion of ANGPT-2 stimulated by growth factors, inhibits ANGPT-1/Tie2 signaling pathway (The function of ANGPT-1 is antagonistic). While, ANGPT-2 could bind to integrin to enhance angiogenesis $[46,47]$. Figure 3 shows the role of ANGPT-1 and ANGPT-2 in angiogenesis.

\section{Fibroblast growth factors (FGFs)}

Fibroblast growth factors (FGFs) are a large family of homologous peptides. Basic fibroblast growth factor (bFGF) is one of the most studied growth factors in cancer and angiogenesis studies [51]. As a result of its effects on endothelial cells and smooth muscle cells, bFGF induces angiogenesis as well as its function as a chemoattractant and aids in the survival and proliferation of epithelial cells and fibroblasts [52].

Angiogenic properties of bFGF have been investigated by various authors in chick embryo chorioallantoic membranes (CAM) and rodent corneas [53, 54]. In addition to investigating the direct impact of bFGF on endothelial cell proliferation, Stavri et al. investigated the potential for bFGF to act indirectly through the upregulation of VEGF expression in vascular smooth muscle cells. They demonstrated that bFGF could also play an indirect role in stimulating angiogenesis by promoting VEGF expression [55]. An in vivo study conducted by Asahara et al. investigated the synergistic effect of VEGF and bFGF on the rabbit hind limb ischaemia model. The findings indicated a significant increase in angiogenesis when both growth factors were used together for treatment [56]. In 2007, Doi et al. produced a gelatin hydrogel-based controlled release system for bFGF. The effects of sustained release of bFGF on angiogenesis were evaluated in rabbits following removal of the femoral artery. bFGF 


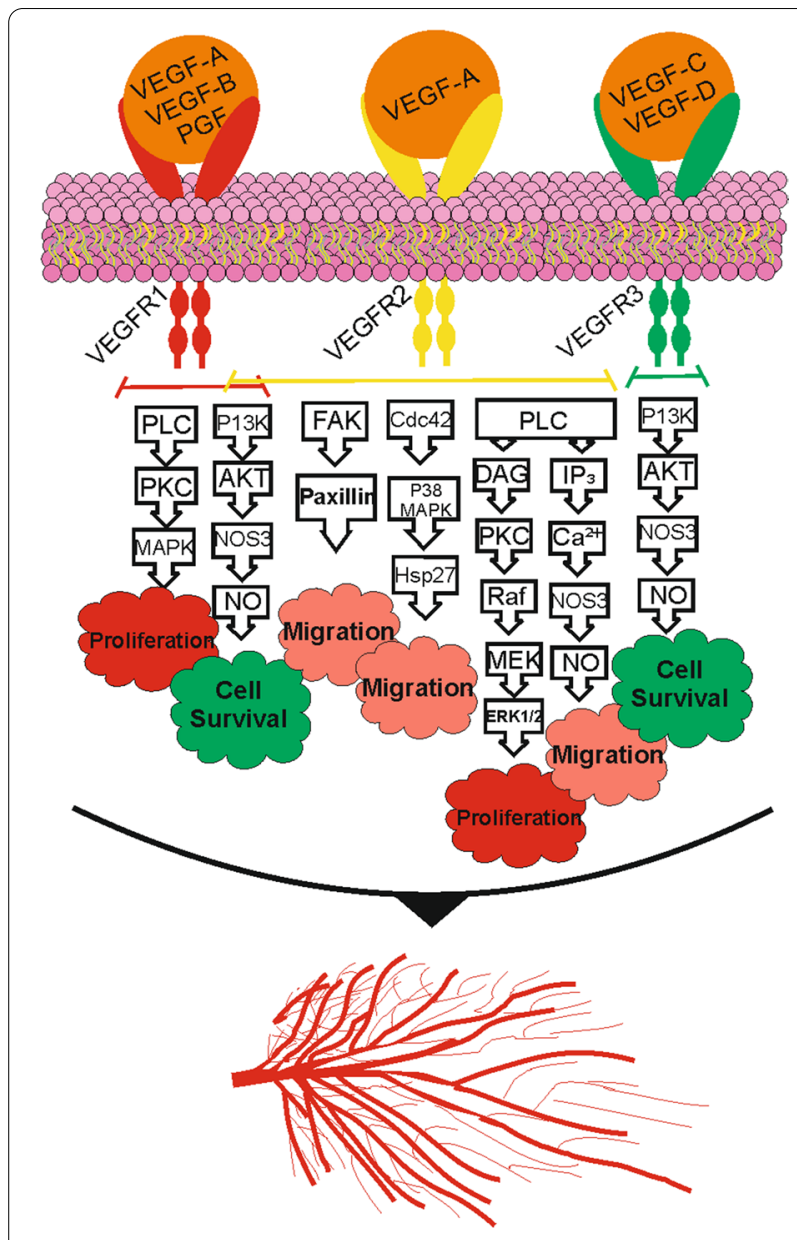

Fig. 2 Signaling pathways induced by VEGF receptors following binding to their ligands [31-40]

treatment rabbits showed a concentration-dependent increase in vascular density, tissue perfusion and arteriole counts [57]. Recently, Yoo et al. have produced visible light-cured glycol chitosan hydrogels containing bFGF and EGF to accelerate the full-thickness wound healing process in Balb/C mice [58].

The following section discusses the common delivery systems used in chronic wound healing applications.

\section{Common approaches}

Common approaches to improve angiogenesis are based on delivery systems (usually cells, proteins and growth factors) $[59,60]$. The main issues of these systems are the short half-life of angiogenic factors and poor intake [61]. An alternative system for long-term induction of angiogenesis is the delivery of efficient genes to the injured tissue. The advantages of gene delivery systems are significant compared to protein delivery, which includes long-term expression and secretion of the angiogenic factor at the injured site, high efficacy, lower side effects,

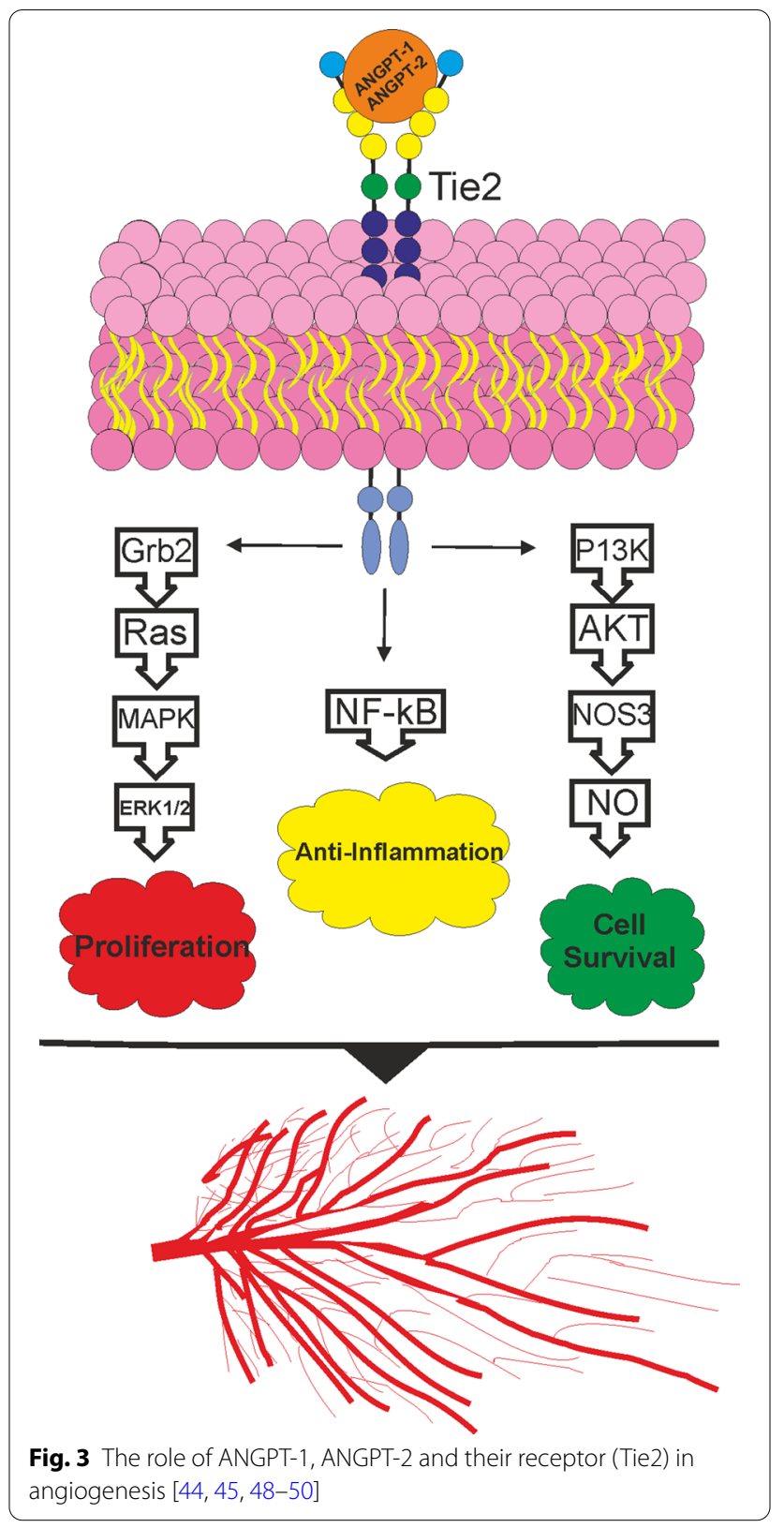

and increased activity [62, 63]. As an example, MicroRNA-135a-3p accelerates the process of angiogenesis by affecting the p38 signaling pathway in diabetic rodents, resulting in more effective wound healing [64]. Stimulating hormones, such as erythropoietin, are also used to improve the efficacy of the treatment [65]. Another approach is to use potent mesenchymal stem cells to enhance angiogenesis in the wound healing process [66].

Recent progress in nanobiotechnology has significantly improved potential applications in delivery systems. Nanobiomaterials exhibit appropriate physico-chemical properties to be used in medicine and in 
different fields of biology [67]. High surface/volume ratio, acceptable biocompatibility, loading efficiency and surface-modification capability are considered to be the most significant advantages of nanomaterials [68]. Based on these properties, a number of investigations have been conducted in the field of skin regeneration using nanomaterials in different ways. Some of these nanomaterials induce angiogenesis due to their unique physico-chemical characteristics $[69,70]$. Bioglass nanoparticles (BG-NPs), some of metal-based nanoparticles, graphene-based nanomaterials and carbon nanotubes (CNTs) are examples of these angiogenic nanomaterials. Angiogenic nanomaterials could be incorporated into engineered structures such as scaffolds [71]. Scaffolds could be prepared from a wide range of natural or synthetic biomaterials. These biomaterials are usually biodegradable, which provide a slow release system for angiogenic nanomaterials to be released at an appropriate rate [72].

In the following sections, we will discuss appropriate characteristics of skin scaffolds, angiogenic nanomaterials and the applications of the incorporated scaffolds for wound healing and skin tissue engineering.

\section{Appropriate characteristics of a skin scaffold Mechanical properties}

Scaffolds that are intended to be used for wound healing applications should have appropriate mechanical properties that can support cellular activities such as proliferation, migration and angiogenesis, as well as to protect structures found in native skin such as blood vessels, lymphatic systems and nerve bundles [73]. For this purpose, the skin scaffold should have mechanical properties similar to those found in native tissue. In this regard, the values of the tensile strengths, the Young's modulus and the elongation-to-break are the most important parameters for assessing the suitability of the mechanical properties of the scaffold [74]. Although these values vary depending on the region of the native tissue, but according to the literature, the tensile strength between 5 and $40 \mathrm{MPa}$, the Young's modulus between 4.5 and $25 \mathrm{MPa}$, and the elongation-to-break between 35 and 120\% seem to be appropriate for wound dressings [75, 76]. Such values provide sufficient mechanical support for angiogenesis and tissue remodeling processes during wound healing and also prevent the side effects of stress shielding [77]. Many studies have shown the excellent mechanical properties of synthetic polymers such as polycaprolactone (PCL), polyurethane (PU) and poly (lactic-co-glycolic acid) (PLGA) due to their thermal and chemical stability $[78,79]$. These polymers could also be blended with natural polymers such as chitosan, collage and gelatin, which have excellent biocompatibility in order to improve their mechanical properties [80-82].

\section{Porosity}

In the field of skin tissue engineering, the porosity of a scaffold is critical to provide adequate spaces for cell accommodation, proliferation, migration and differentiation. Porous scaffolds also facilitate the oxygenation and nutrition of the wounded skin through the 3D matrix [83]. Some studies have shown that scaffolds with 60 to $90 \%$ porosity are suitable for wound healing applications as they are capable of providing the sufficient space for cell activity, oxygen and nutrient exchange, and the production of a new ECM [84]. Since the increase in the porosity of a scaffold has a direct effect on the reduction of the mechanical parameters mentioned above, the balance between the porosity and the mechanical properties of the scaffold is critical [85]. In order to prevent a significant reduction in the mechanical properties of the scaffold, nanobiomaterials such as carbon nanotubes and ceramic or metallic nanoparticles can be used which, in addition to increasing the mechanical properties, also stimulate angiogenesis $[86,87]$.

\section{Surface wettability of skin scaffolds}

Wettability is one of the most significant features of the material's surface. The surface hydrophilicity of skin scaffolds is a critical parameter that affects cell attachment, proliferation and differentiation [88]. The wettability of the scaffolds is usually determined by measuring the water contact angle at the surface of the scaffold [89]. According to other studies, moderate hydrophilic surfaces with a water contact angle between 30 and $70^{\circ}$ have been shown to encourage cells to adhere and expand [90]. On the other hand, hydrophobic and highly hydrophobic surfaces exhibited lower cell adhesion. Presence of hydrophilic functional groups such as hydroxyl, esters and amides in the structure of many natural-based biopolymers make these biomaterials suitable to be used for skin tissue engineering applications [85]. Since the first step in angiogenesis is the attachment of cells to the scaffold, natural-based scaffolds incorporated with angiogenic nanobiomaterials are suitable for enhancing angiogenesis during the wound healing process. Hydrophilic wound dressings and skin scaffolds are also capable of providing moist environments that promote the healing process [91].

\section{Water vapor transmission rate and water uptake ability}

As mentioned above, in addition to providing a moist environment, the ideal skin scaffold or wound dressing should also prevent dehydration of the wound and be 
able to remove the excessive wound exudate [92]. In this regard, an ideal skin scaffold should have a water absorption capacity of 100 to $800 \%$ (compared to its dry weight) to prevent the accumulation of fluids in order to enhance the formation of the new ECM [93, 94]. The accumulation of wound exudate at the injured site results in the degradation of ECM components and involvement of the surrounding tissues, which causes excessive pain to the patient [91]. In addition, it has been shown that skin scaffolds with water vapor transmission values ranging from 2000 to $2500 \mathrm{~g} / \mathrm{m} 2 /$ day provide sufficient moisture and prevent the accumulation of wound exudate. Low water vapor transmission rates prevent gaseous exchanges leading to an accumulation of $\mathrm{CO}_{2}$ that can lead to the acidification of the wound media. This condition could have a direct impact on the regeneration of the injured tissue by inhibiting cell proliferation during angiogenesis. It is also provide an appropriate environment for the growth of anaerobic bacteria. On the other hand, high water vapor transmission rates can also lead to dehydration of the wound $[91,95]$.

\section{Degradation rate and release profile}

In the case of biodegradable skin scaffolds, degradation rate and release profile are important parameters that should be considered. The higher degradation rate of the scaffold leads to the higher release rate of the incorporated bioactive factor [96]. On the other hand, the degradation rate of the skin scaffold should be proportional to the healing rate of the wounded skin [97]. Incorporation of nanobiomaterials can affect the physicochemical properties of the scaffolds and therefore their degradation rate and release profile [98]. Other important factors that can directly affect these two parameters are cross-linkers and crosslinking procedures. Chemical crosslinkers such as glutaraldehyde and $N$-ethyl- $N^{\prime}$-(3-(dimethylamino) propyl) carbodiimide/ $N$-hydroxysuccinimide (EDC/ NHS) significantly reduce the rate of degradation of a wide range of biopolymers in both in vitro and in vivo aquatic environments. The cross-linking time and type of cross-linker should therefore be optimized according to the type of wound and the severity of the injury [99]. High levels of some angiogenic nanobiomaterials, such as metallic- and ceramic-based nanoparticles, could induce dose-dependent toxicity. The incorporation of high levels of these nanoparticles into scaffolds with an appropriate rate of degradation could provide a slow-release system that can stimulate angiogenesis without inducing dosedependent toxicity $[100,101]$.

\section{Protein adsorption}

When the skin scaffold is placed at the injured site, it is immediately exposed to proteins in the body's fluids. The proteins are attached to the surface of the scaffold and provide an adhesive surface. Albumin is the most abundant protein in serum and after an injury occurs this protein is accumulated at the wound site. Subsequently, the absorbed albumin is replaced by fibronectin and vitronectin. The protein-coated surface could induce cell adhesion through membrane receptors [102]. As mentioned earlier, cell adhesion is the first step for angiogenesis. This could have a direct effect on skin scaffold biocompatibility [103]. Evaluation of albumin absorption can be an appropriate index to determine the ability of a skin scaffold or wound dressing to absorb proteins $[85,104]$.

Table 1 summarizes appropriate characteristics of a skin scaffold.

\section{Angiogenic nanobiomaterials Metal nanoparticles}

A wide range of metal-based nanoparticles have been widely used as angiogenic treatments for wound healing and skin regeneration. Zinc oxide nanoparticles $(\mathrm{ZnO}-$ $\mathrm{NPs}$ ) have been shown to induce endothelial cell migration and enhance blood vessel formation by producing nitric oxide (NO) through the MAPK/Akt/eNOS pathway [105].

Table 1 Appropriate characteristics of a skin scaffold

\begin{tabular}{|c|c|c|}
\hline & Characteristics & Value \\
\hline \multirow[t]{3}{*}{ Mechanical properties } & Young's modulus & 4.5-25 MPa \\
\hline & Tensile strength & $5-40 \mathrm{MPa}$ \\
\hline & Elongation-to-break & $35-120 \%$ \\
\hline \multirow[t]{5}{*}{ Physicochemical properties } & Porosity & $60-90 \%$ \\
\hline & Surface wettability (water contact angle) & $30-70^{\circ}$ \\
\hline & water uptake ability & $100-800 \%$ \\
\hline & Water vapor transmission rate & $2000-2500 \mathrm{~g} / \mathrm{m}^{2} /$ day \\
\hline & Degradation rate and release profile & $\mathrm{N} / \mathrm{A}$ \\
\hline \multirow[t]{2}{*}{ Biological properties } & Albumin adsorption & 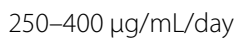 \\
\hline & Cell viability & $\mathrm{N} / \mathrm{A}$ \\
\hline
\end{tabular}


The incorporation of $\mathrm{ZnO}$-NPs in scaffolds is a promising approach for skin tissue engineering applications. PCL/ $\mathrm{ZnO}-\mathrm{NPs}$ electrospun membrane was fabricated and characterized by Augustine et al. Increased proliferation of dermal fibroblast cells and upregulated expression of FGF2 and VEGF-A were reported. The results showed the potential of the electrospun membrane for vascular regeneration in wound healing [106].

The angiogenic properties of cerium oxide nanoparticles $\left(\mathrm{CeO}_{2}\right.$-NPs $)$ have been investigated in several studies. One of the most important investigations is a study by Das et al. They have demonstrated that $\mathrm{CeO}_{2}-\mathrm{NPs}$ stimulate pro-angiogenesis, depending on surface valance states. In vitro studies showed the formation of tube structures in the presence of $\mathrm{CeO}_{2}$-NPs. Vascular sprouting was the main result of in vivo studies to confirm the angiogenic activity of $\mathrm{CeO}_{2}$-NPs. The main causes of angiogenesis induction were stated to be stabilization of HIF- $1 \alpha$ in endothelial cells and altered gene regulation [107]. The size of the $\mathrm{CeO}_{2}-\mathrm{NPs}$ and the ratio of $\mathrm{Ce}^{3+} / \mathrm{Ce}^{4+}$ are the parameters that could affect the angiogenic properties of the nanoparticles [108]. Another study demonstrated increased proliferation of endothelial cells, fibroblasts and keratinocytes in the presence of low concentrations of $\mathrm{CeO}_{2}$-NPs [109]. $\mathrm{CeO}_{2}$-NPs could be incorporated into polymeric scaffolds to be used as an angiogenic structure in tissue engineering. $\mathrm{PCL} / \mathrm{CeO}_{2}-$ NP nanocomposite membrane has been shown to be capable of promoting angiogenesis following subcutaneous implantation in rats due to the stability of HIF- $1 \alpha$ and increased expression of VEGF [110].

Gold nanoparticles (Au-NPs) are commonly used in medical applications due to their unique physico-chemical properties. Au-NPs can scavenge reactive oxygen species (ROS) through antioxidant activity [111]. High surface-tovolume ratio of nanoparticles, make them more efficient. Using $\mathrm{Au}-\mathrm{NPs}$ in photobiomodulation-based therapy accelerates the process of wound healing by improving angiogenesis as well as the proliferation of epithelial cells and the formation of collagen [112]. A study by Kim et al. showed that hydrocolloid membranes coated with chemically stabilized Au-NPs could be used for wound healing applications. Up-regulated expression of the ANGPT-1, ANGPT-2, VEGF and collagen genes confirmed the angiogenic properties of these stabilized nanoparticles [113]. Another approach is to use surface engineered Au-NPs as a delivery system to deliver angiogenic factors such as VEGF, as reported by Chen et al. [114].

\section{Bioactive glasses (BGs)}

BG is a series of specially designed silica-based glasses where the $3 \mathrm{D} \mathrm{SiO}_{2}$ network is modified by the addition of $\mathrm{CaO}, \mathrm{Na}_{2} \mathrm{O}$ and $\mathrm{P}_{2} \mathrm{O}_{5}$ [115]. BGs were first introduced in 1969 and described as a group of reactive biomaterials capable of bonding to mineralized bone tissue under physiological conditions. The first biomedical application of BGs was in the form of solid pieces for small bone replacements in middle ear surgery [116]. The most common BG is called 45S5, consisting of 45 wt $\% \mathrm{SiO}_{2}, 24.5$ wt $\% \mathrm{CaO}, 24.5$ wt $\% \mathrm{Na}_{2} \mathrm{O}$, and 6.0 wt $\% \mathrm{P}_{2} \mathrm{O}_{5}$. By mixing the different ratios of these four oxides, different BGs have been produced to enhance their inherent properties; additional oxides may also be used to improve specific therapeutic actions [115]. In recent years, BGs have been widely investigated for potential applications in the fields of regenerative medicine and tissue engineering due to their ability to increase angiogenesis and osteogenesis $[117,118]$. BGs have attracted a great deal of interest, as their ion dissolution products have been identified to improve angiogenesis, which plays a key role in wound healing (Fig. 4).

BG-NPs have shown more advantages than conventional BGs, such as better biocompatibility, faster dissolution of ions, higher specific surface area, increased cell attachment, etc. BG-NPs are known as angiogenic nanobiomaterials and recent interest in BG-NPs increased in tissue engineering due to the dependence of accelerated wound healing on angiogenic materials [126, 127]. As the interest in BG-NPs increased, different methods of synthesis were developed. Gas phase (flame spray), microemulsion techniques, laser spinning, and sol-gel are the current BG-NP synthesis methods. The sol-gel method is the most common. BGs synthesized by the sol-gel method have an inherent mesoporous structure with a pore size of approximately 4-60 nm, which allows growth factors and drugs to be placed in nano-sized pores and then released locally in a controlled manner [128].

Some metal ions have been shown to increase angiogenesis by affecting key factors. The optional addition of these ions (e.g. $\mathrm{Mg}^{2+}, \mathrm{Cu}^{2+}$ ) to the BG-NPs could therefore promote the angiogenic properties of the particles and make them interesting to be used to accelerate the healing process (Table 2). In addition, ion-loaded BGNPs could be incorporated into other polymeric biomaterials to improve their mechanical and biological properties. Such nanocomposite scaffolds have shown a good potential for wound healing and skin tissue engineering applications $[87,129]$.

Biodegradable tiny cotton-candy borate BG (MoSci Corp., Rolla, MO, USA), imitating the microstructure of a fibrin clot, was reported to improve wound healing in both animals and human patients. These BG nanofibers (basic 13-93 $\mathrm{B}_{3}$ composition: $53 \mathrm{~B}_{2} \mathrm{O}_{3}-6 \mathrm{Na}_{2} \mathrm{O}-12 \mathrm{~K}_{2} \mathrm{O}-5 \mathrm{MgO}-20 \mathrm{CaO}-4 \mathrm{P}_{2} \mathrm{O}_{5}$ wt \%), trade-named as DermaFuse $^{\mathrm{TM}} /$ Mirragen $^{\mathrm{TM}}$, help impressively the healing of long-term venous stasis ulcers in 


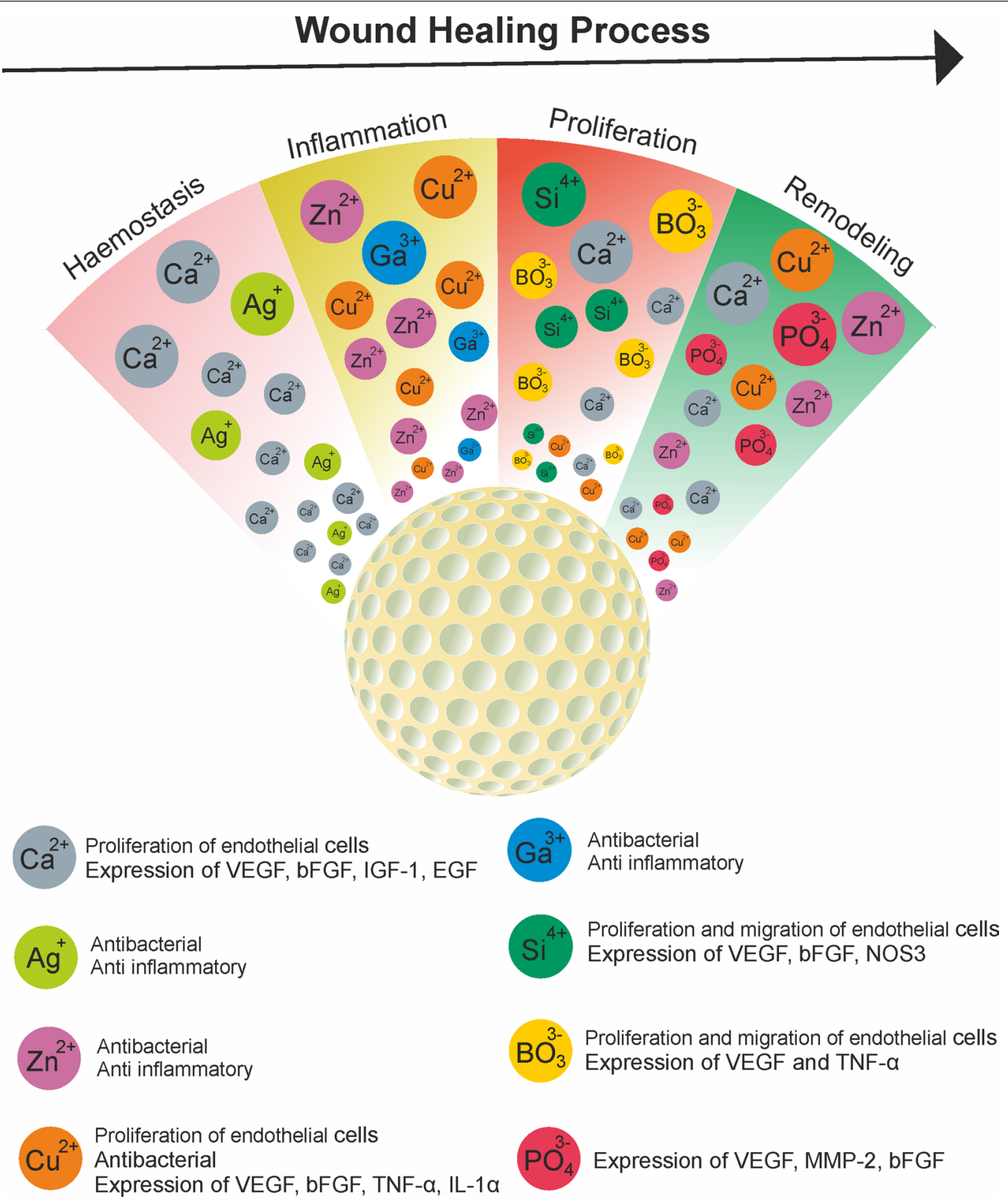

Fig. 4 lons release from incorporated mesoporous BG during the wound healing process [119-125]

diabetic patients, who were irresponsive conventional treatment [130]. Studies carried out in a rat subcutaneous model showed that the angiogenetic effect can be further accelerated by doping the BG with small amounts of copper that is locally released into the biological environment [131].

\section{Carbon nanotubes (CNTs)}

CNTs are cylindrical molecules composed of singlelayer carbon atom rolled-up sheets. CNTs have two single-walled and multi-walled forms. Single-walled carbon nanotubes (SWCNTs) have a diameter of approximately $1 \mathrm{~nm}$ or less. Multi-walled carbon nanotubes (MWCNTs) consist of several concentric nanotubes with a total diameter of more than $100 \mathrm{~nm}$. The length of these structures is variable and may reach several micrometers or even millimeters depending on their use [142]. Nanostructure, large specific surface area, electrical conductivity and good mechanical properties make CNTs suitable for biomedical applications such as biosensors, drug and gene delivery systems, tissue engineering and regenerative 
Table 2 Angiogenic ions incorporated in BG-NPs [127, 132-141]

\begin{tabular}{|c|c|c|c|c|}
\hline Angiogenic Element & BG Type & In vitro (cell type)/in vivo (animal model) & Results & Refs. \\
\hline Calcium silicate & $45 S 5$ BG & In vitro (HUVECs) & $\begin{array}{l}\text { Increased expression of VEGF, bFGF, KDR, } \\
\text { bFGFR and NOS3 genes in HUVECs }\end{array}$ & {$[132]$} \\
\hline Boron & $45 S 5$ BG & In vivo (CAM of quail embryos) & $\begin{array}{l}\text { Increased expression of integrin } a_{v} \beta_{3} \\
\text { Increased number of blood vessels }\end{array}$ & {$[133]$} \\
\hline Copper & Borate BG & $\begin{array}{l}\text { In vitro (hBMSCs)/in vivo (rat with calvarial } \\
\text { defects) }\end{array}$ & $\begin{array}{l}\text { Increased in vitro proliferation of hBMSCs, For- } \\
\text { mation of new blood vessels was confirmed } \\
\text { by IHC staining for CD31 }\end{array}$ & {$[134]$} \\
\hline Cobalt and Strontium & $45 S 5$ BG & $\begin{array}{l}\text { In vitro (HUCPVCs)/in vivo (defect in the distal } \\
\text { femur of rabbit animal model) }\end{array}$ & $\begin{array}{l}\text { Increased expression level of VEGF gene in the } \\
\text { HUCPVCs, formation of new blood vessels } \\
\text { was confirmed by IHC staining for VEGF } \\
\text { protein }\end{array}$ & {$[135]$} \\
\hline Silicon & S53P4 BG & In vitro (Human CD-18CO fibroblasts) & $\begin{array}{l}\text { Increased proliferation of fibroblast cells, } \\
\text { Increased secretion of VEGF, stimulation of } \\
\text { neovascularization }\end{array}$ & {$[136]$} \\
\hline Magnesium & Silicate BG & In vitro (HAECs)/in vivo (rabbit bone defect) & $\begin{array}{l}\text { Increased proliferation of HAECs, HAECs align- } \\
\text { ment and exhibition of branch nodes that } \\
\text { is a phenomenon of the primary stage of } \\
\text { angiogenesis, Increased NOS3 gene expres- } \\
\text { sion, Promoted angiogenesis in the defect } \\
\text { area }\end{array}$ & {$[137]$} \\
\hline Europium & Mesoporous BG 4555 & $\begin{array}{l}\text { In vitro (HUVECs)/in vivo (Mice with full-thick- } \\
\text { ness wound) }\end{array}$ & $\begin{array}{l}\text { Upregulated angiogenesis-related genes } \\
\text { (MMP9, VEGFR1/2, CD31 and PDGFR a/ } \beta \text { ) of } \\
\text { HUVECs, blood vessel formation, collagen } \\
\text { deposition and re-epithelialization at chronic } \\
\text { skin wound sites }\end{array}$ & {$[138]$} \\
\hline Niobium & $45 S 5 B G$ & In vitro (ST-2 bone marrow stromal cells) & $\begin{array}{l}\text { Improved proliferation of bone marrow stro- } \\
\text { mal cells, significant increase in VEGF release }\end{array}$ & {$[139]$} \\
\hline Strontium & Borate BG & $\begin{array}{l}\text { In vitro (hBMSCs)/in vivo (Critical-sized rabbit } \\
\text { femoral condyle defect model) }\end{array}$ & $\begin{array}{l}\text { Increased proliferation of hBMSCs, Upregu- } \\
\text { lated expression of genes associated with } \\
\text { angiogenesis and osteogenesis, such as } \\
\text { VEGF, RUNX2, BMP-2, and osteopontin }\end{array}$ & {$[140]$} \\
\hline Strontium and Copper & $45 S 5$ BG & In vitro (hBMSCs, HUVECS) & $\begin{array}{l}\text { Differentiation of hBMSCs to vascular endothe- } \\
\text { lial cells, formation of tubular and nodal } \\
\text { networks of HUVECs }\end{array}$ & {$[127]$} \\
\hline
\end{tabular}

HUVECs human umblical vein endothelial cells, CAM chorioallantoic membrane, hBMSCs human bone marrow stem cells, HUCPVCs human umbilical cord perivascular cells, HAECs human amniotic epithelial cells

medicine $[86,143,144]$. It has been shown that VEGF and matrix metalloprotein-9 (MMP-9), which are involved in angiogenesis and tissue remodeling, could be released by stimulated macrophages exposed to CNTs [139]. CNTs could be modified in order to be functionalized for angiogenesis regulation. Polyamine-coated CNTs were used as a micro-RNA delivery system to regulate angiogenesis by targeting endothelial cells [145]. In another study, Liu et al. treated the surface of CNTs with plasma. Then, VEGF was loaded onto the nanotubes to provide a new system with controlled release of VEGF. In the next step, porcine small intestinal submucosa was exposed to these modified VEGF-loaded CNTs. Results showed a statistically significant increase in angiogenesis during repair of the abdominal wall defect [146]. Using CNTs in the structure of polymeric scaffolds could also provide a suitable mechanical strength and give them biological advantages as studied by Lalwani et al. [147].

\section{Graphene-based nanomaterials}

Graphene is a monolayer of carbon atoms bound in a honeycomb-like lattice with a two-dimensional $\mathrm{sp}^{2}$ structure. Such a unique structure is responsible for many specific properties of graphene, such as excellent mechanical properties, large surface area and exceptional thermal conductivity [148]. The potential of graphene was first explored for use in energy storage and sensors. The first biomedical use of graphene dates back to 2008 when it was introduced as a drug delivery carrier [149]. Since then, graphene has been considered as a potent biomaterial to be used in biomedical research. Biosensors, nanomedicine, delivery systems, imaging, diagnostics, regenerative medicine, biomedical and tissue engineering are the biological fields in which graphene-based materials are used [150-152].

Graphene oxide is one of the graphene-based materials with angiogenic properties. Graphene oxide is a unique graphene that is chemically modified and contains oxygen-containing functional groups (such as 
carboxylic acid, alcohol, hydroxyl, epoxide and carbonyl) in its structure with approximately three to one carbon/ oxygen ratio. Over the last decade, graphene oxide has been widely used in biomedical applications [153, 154]. Angiogenic properties of graphene were investigated in a study conducted by Norahan et al., which demonstrated improved angiogenesis due to the use of a cardiac patch composed of collagen/graphene [155]. Appropriate concentrations of graphene oxide and its reduced form have been shown to enhance angiogenesis by induction of ROS production. Concentrations less than $100 \mathrm{ng}$ have been reported to stimulate angiogenesis. Higher concentrations induce cell toxicity and inhibit angiogenesis $[156,157]$. Qian et al. developed a 3D graphene oxide/ PCL composite scaffold to regenerate injured sciatic nerves in vivo by promoting angiogenesis. Results confirmed upregulation of the PI3K/Akt/eNOS/VEGF signaling pathway compared to the control group (treated with PCL scaffold) which demonstrated the enhanced angiogenesis due to the presence of graphene oxide [158]. Nyambat et al. produced an adipose stem cell derived ECM-nano graphene oxide composite sponge for skin regeneration. The results showed the potential of the biocompatible angiogenic scaffold for skin tissue engineering applications [159].

\section{Europium hydroxide}

Lanthanides are widely used elements in scientific research that have attracted researchers in immunoassay and biological imaging studies in recent years. Europium is the most reactive lanthanide that has been studied as a potent element to enhance angiogenesis in biological investigations in recent decades [160]. In 2008, Patra et al. studied the interaction between europium (III) hydroxide nanorods with human umbilical vein endothelial cells (HUVECs) to evaluate pro-angiogenic properties of these nanorods. The results showed the internalization of the nanorods to the HUVECs. Chick chorio-allantoic membrane assay of HUVECS treated with the europium (III) hydroxide nanorods demonstrated vascular formation due to increased angiogenesis [161]. The molecular mechanism of angiogenesis induced by europium hydroxide nanorods was first suggested by Nethi et al. in 2015. Europium hydroxide nanorods has been shown to induce $\mathrm{H}_{2} \mathrm{O}_{2}$ production that activates the enzyme nitric oxide synthase 3 (NOS3) which has a protective function in the cardiovascular system. NOS3 triggers the PI3K/Akt signaling pathway to increase nitric oxide (NO) secretion, leading to angiogenesis [156]. The mechanism of angiogenesis induced by europium hydroxide nanorods is presented in Fig. 5.

The results obtained from such studies introduce europium oxide nanorods as a potent angiogenic material for

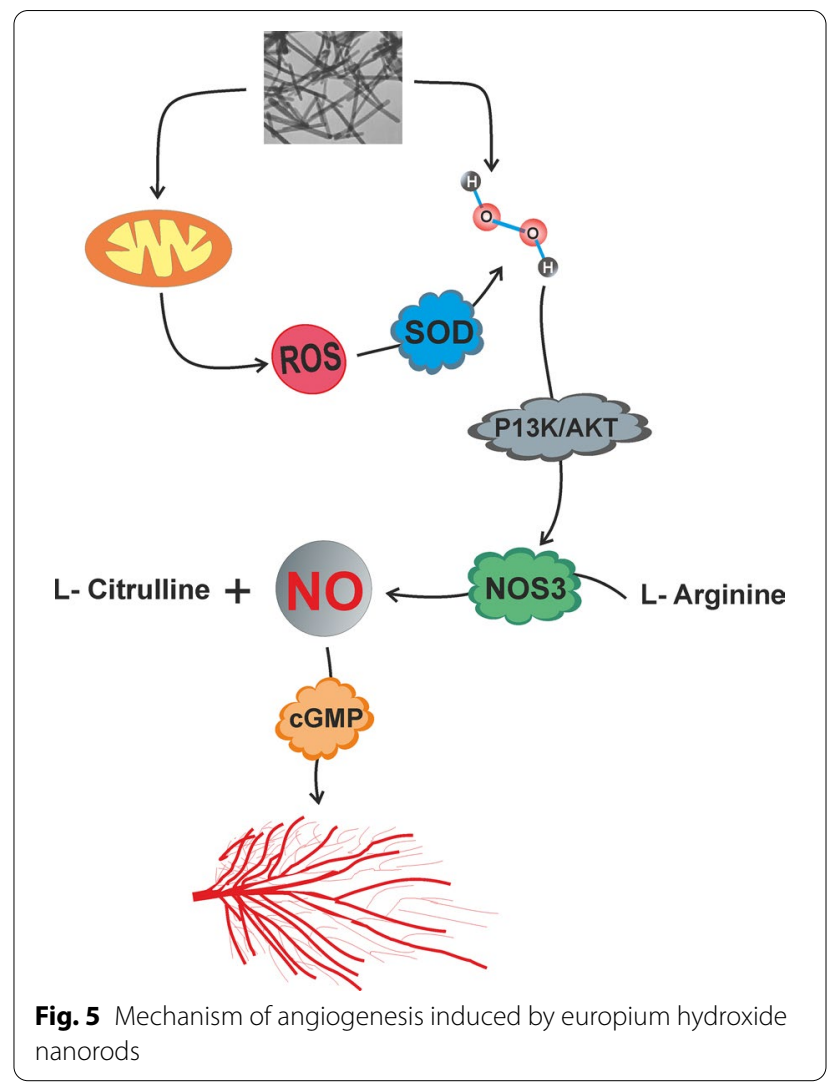

use in tissue engineering applications. Europium oxide nanorods/PCL electrospun membrane has been shown to increase the rate of angiogenesis in chicken embryos compared to PCL electrospun membrane. The angiogenic activity was attributed to the ability of the scaffold to activate the VEGFR2/Akt signaling pathway due to the presence of europium oxide nanorods [162].

\section{Skin tissue engineering}

New nanomaterial-based treatments for skin wounds have been developed in recent years. Several in vitro (studies conducted on endothelial cells such as HUVECs) and in vivo (rats, mice, rabbits and guinea pig models) studies have confirmed the efficacy of nanocomposite scaffolds on angiogenesis $[16,163]$. Nanoparticles are widely used as an effective part of composite scaffolds to accelerate the healing process of chronic wounds through their various properties, such as angiogenic, anti-inflammatory and anti-bacterial properties [164]. Many clinical trials have been developed for skin regeneration based on nanoparticles, but Acticoat ${ }^{\circledR}$ is the only US FDA approved nanoparticle-based skin product. The wound dressing contains silver nanoparticles that could be released slowly during the healing process. The antibacterial properties of these nanoparticles minimize the need for several wound 
dressings to be used during the healing of chronic wounds and also reduce the inflammatory response [165]. There is still no FDA-approved skin product with angiogenic nanomaterials in its structure, but the emerging number of related studies shows the potential of these nanobiomaterials for skin regeneration. The development of new techniques and methods facilitated the use of angiogenic factors, materials and nanoparticles in engineered structures and delivery systems [166]. However, a wide range of biomaterials have been characterized and used as composite and nanocomposite skin scaffolds, but there are many biological, engineering and clinical challenges that need to be considered. A summary of some of these challenges is presented in Table 3.

(Hydro-) gels are promising materials with great potential for development in the field of biology and medicine. They are widely used in wound healing and skin tissue engineering applications in a variety of ways [171]. (Hydro-) gel-based scaffolds usually exhibit appropriate biological properties despite their mechanical properties. The formation of (hydro-) gels with appropriate mechanical properties is challenging due to their natural low mechanical strength. The incorporation of nanomaterials is one of the feasible solutions for improving their stiffness. On the other hand, the structural network of (hydro-) gels provides an adhesive environment for nanostructures to present their biological properties more efficiently [172, 173]. The incorporation of nanostructures gives hydrogels specific properties that improve wound healing. Hydrogels incorporated with $\mathrm{ZnO}$-NPs have been shown to support angiogenesis as studied by Ahtzaz et al. [174]. Adding graphene oxide-based nanomaterials to hydrogels can enhance cell attachment to improve angiogenesis in tissue engineering applications [175]. The incorporation of silicate BG-NPs into hydrogels supports the bonding of biomaterials and wounded tissues [87]. In a recent study by $\mathrm{Li}$ et al., silica-based nanocomposites hydrogel scaffolds were fabricated for enhancing angiogenesis to accelerate diabetic wound healing. Polyethylene glycol diacrylate (PEGDA) was used as the main network of the nanocomposite scaffold. Copper-containing BG-NPs and sodium alginate were added to induce angiogenesis. The in vivo results of the study showed increased number of vessels, high levels of blood flow volume, and accelerated wound healing (Fig. 6) [176].
Incorporated (hydro-) gels are used in tissue engineering techniques to produce a wide range of skin scaffolds with angiogenic properties. Nowadays, three dimensional (3D) bio-printing of skin is a popular research area. Biomaterial selection is one of the key steps in this technique and the most common type of biomaterial used is biopolymer-based hydrogels. There is a wide range of natural, synthetic and composite biopolymers available for 3D skin bio-printing, which can be selected based on the type of printing process [177]. Both of the natural and synthetic biopolymers have certain limitations. Despite having the greatest advantage of imitating ECM, natural biopolymers exhibit poor mechanical properties. On the other hand, synthetic biopolymers have the advantage of excellent mechanical properties, but their microstructures are very different from the ECM of native tissue. Researchers therefore prefer to produce composite scaffolds, which have both natural and synthetic polymer components, in order to combine the advantages of both and overcome limitations [178]. Gelatin, chitosan, collagen and silk fibroin are the most common natural biopolymers used in printed skin scaffolds and the synthetic biopolymers are PCL, polylactic acid (PLA), and PLGA. Composite scaffolds are produced by a combination of at least one of each group [179-181].

Some basic requirements for bio-printing, summarized in Table 4, should be considered in order to achieve the optimal properties of skin scaffolds.

More than 200 polymers could produce nano- or microscale fibers using the electrospinning technique. All of these polymers are not proper for biological applications. Biocompatibility is the most important factor that determines whether a material is suitable for biomedical applications or not [188]. After identifying the biocompatibility of a polymer, other features that make a polymeric construct suitable for regeneration of a target tissue should be considered. Mechanical properties and degradation rate are important factors for producing an engineered skin scaffold [189]. Electrospun polymers provide a wide range of skin scaffolds for chronic wound healing applications. The most significant advantage of these types of nanofibrous scaffolds is the high surface/volume ratio that facilitates cell adhesion during the healing process. Biopolymers are used individually or in combination with other biopolymers [190]. Chitosan, alginate, chondroitin, collagen,

Table 3 Biological, engineering and clinical challenges in skin tissue engineering [167-170]

\begin{tabular}{lll}
\hline Biological Challenges & Engineering Challenges & Clinical Challenges \\
\hline $\begin{array}{lll}\text { Selection of a suitable cell source } \\
\text { Repeatable cell differentiation condition }\end{array}$ & Selection of biocompatible material & Adaptation of the scaffold to the surrounding tissue \\
$\begin{array}{l}\text { Selection of growth factors, biomolecules } \\
\text { and bio-active agents }\end{array}$ & Repeatable scaffold fabrication condition & Appropriate volume and shape of the regenerated tissue \\
\end{tabular}



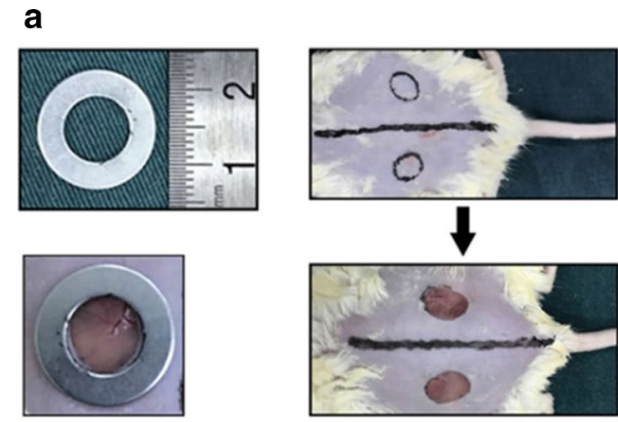

c

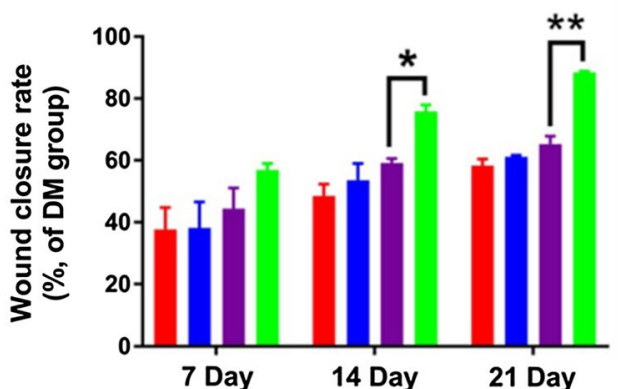

b

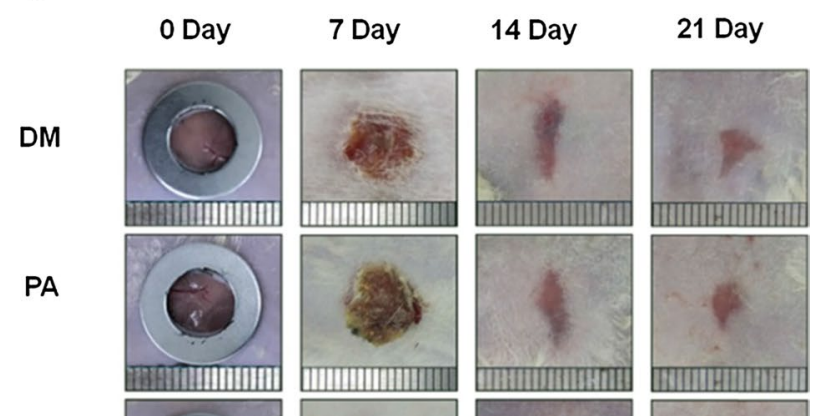

PAB

PABC
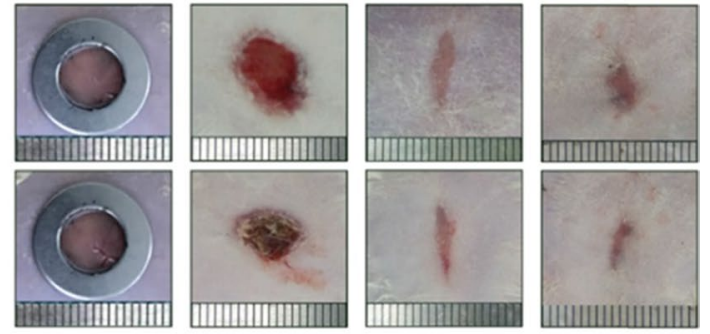

Fig. 6 Effect of hydrogel scaffolds on diabetic wound healing. a Construction of diabetic wound model in ICR mice; $\mathbf{b}$ Wound healing process during 21 days treatment by different scaffolds (PA: PEGDA + sodium alginate, PAB: PEGDA + sodium alginate + BG-NPs, PABC: PEGDA + sodium alginate + copper-containing BG-NPS), DM: Diabetes mellitus wound was used as a control; c Wound closure rates at day 7, 14 and $21 .\left({ }^{*} p<0.05\right.$ and ${ }^{* *} p<0.01$.). Reprinted with Permission from [176]

Table 4 Suitable properties of 3D bio-printing hydrogels [182-187]

\begin{tabular}{|c|c|c|c|c|}
\hline Biocompatibility & Printability & Morphological properties & Mechanical properties & Physicochemical properties \\
\hline Cell toxicity & Rheological properties and viscosity & Porosity percentage & Young's modulus & Wettability \\
\hline Blood toxicity & $\begin{array}{l}\text { Sol-gel transition in response to } \\
\text { temperature change }\end{array}$ & Pore size and shape & Strength & Degradation rate \\
\hline Immunogenicity & Transition time & Micro-/nanostructure & Elasticity & Swelling \\
\hline Protein adsorption & Shear thinning & & Stiffness & Water vapor transition rate \\
\hline Cell attachment & & & Elongation to break & \\
\hline
\end{tabular}

gelatin, fibrin, keratin and silk fibroin are the most common natural polymers used single or blended to provide the electrospun scaffolds for skin tissue engineering [191, 192]. PCL, PLGA, poly (3-hydroxybutyrate-co-3-hydroxyvalerate) (PHBV), poly (etherurethane urea) (PEUU) and poly (glycerol sebacate) (PGS), are the examples of synthetic polymers used for regeneration of damaged skin tissue $[169,193]$. The incorporation of nanostructures into these nano-/micro fibers is a common approach to providing controlled-release functional systems.

Porous polymeric sponges, in combination with nanobiomaterials and growth factor, can provide an appropriate microenvironment for cells homing, migration and differentiation. Porous scaffolds are prepared by different techniques such as freeze drying, particle leaching method and solid freeform fabrication. A wide range of natural and synthetic polymers are used to fabricate such porous scaffolds. Freeze drying is one of the most developed method to fabricate porous sponges. In this method, pores size could be controlled by changing amount of organic solvents and freezing temperature. Gas-foaming and solvent casting/particle leaching also give a suitable control over pores shapes and sizes. Incorporating of organic or inorganic fillers during scaffold preparation process is an efficient way to improve mechanical properties of composite scaffolds [194, 195].

Table 5 summarizes the application of engineered skin scaffolds incorporated with growth factors or nanobiomaterials to induce angiogenesis in wound healing. 


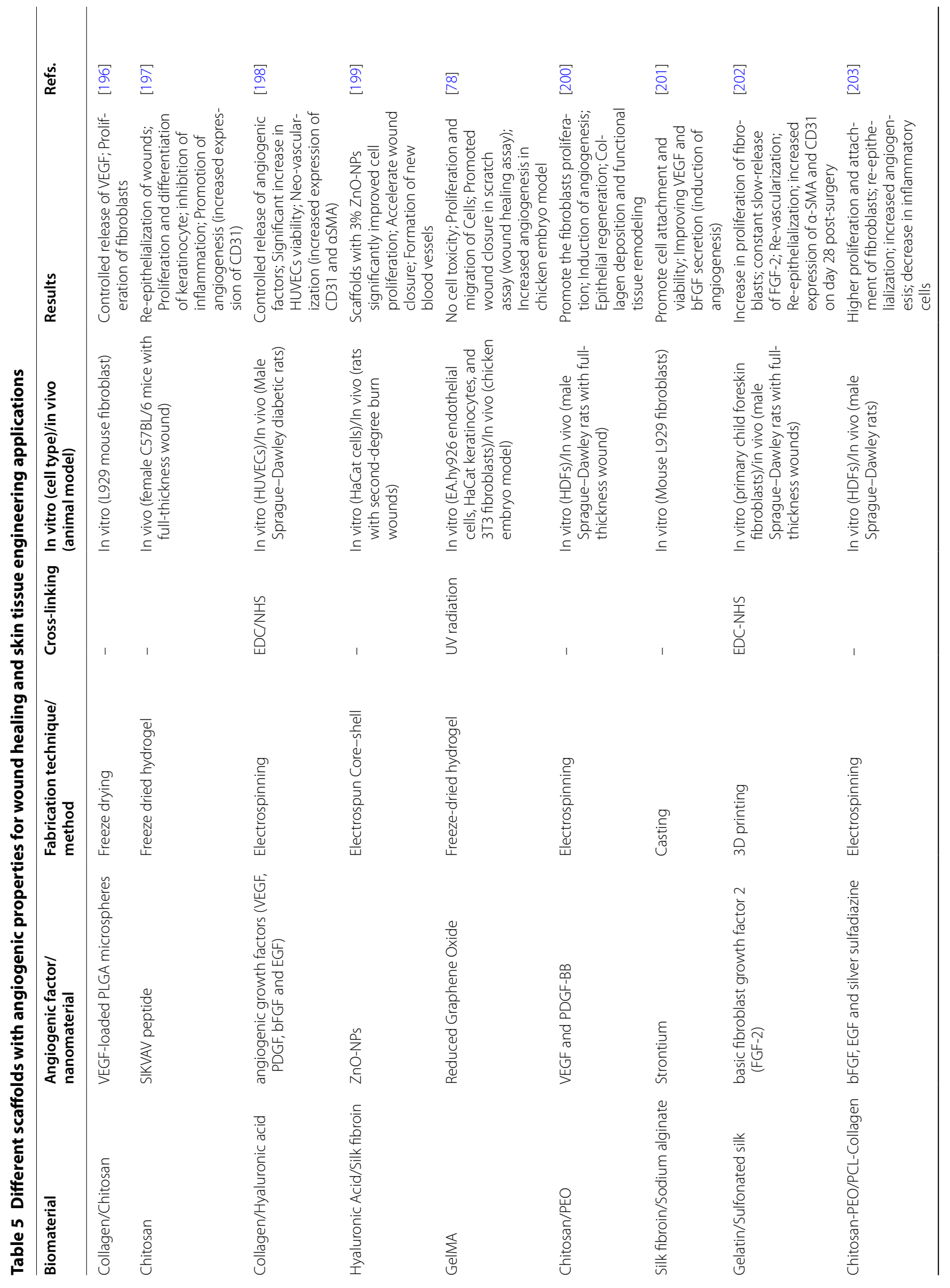




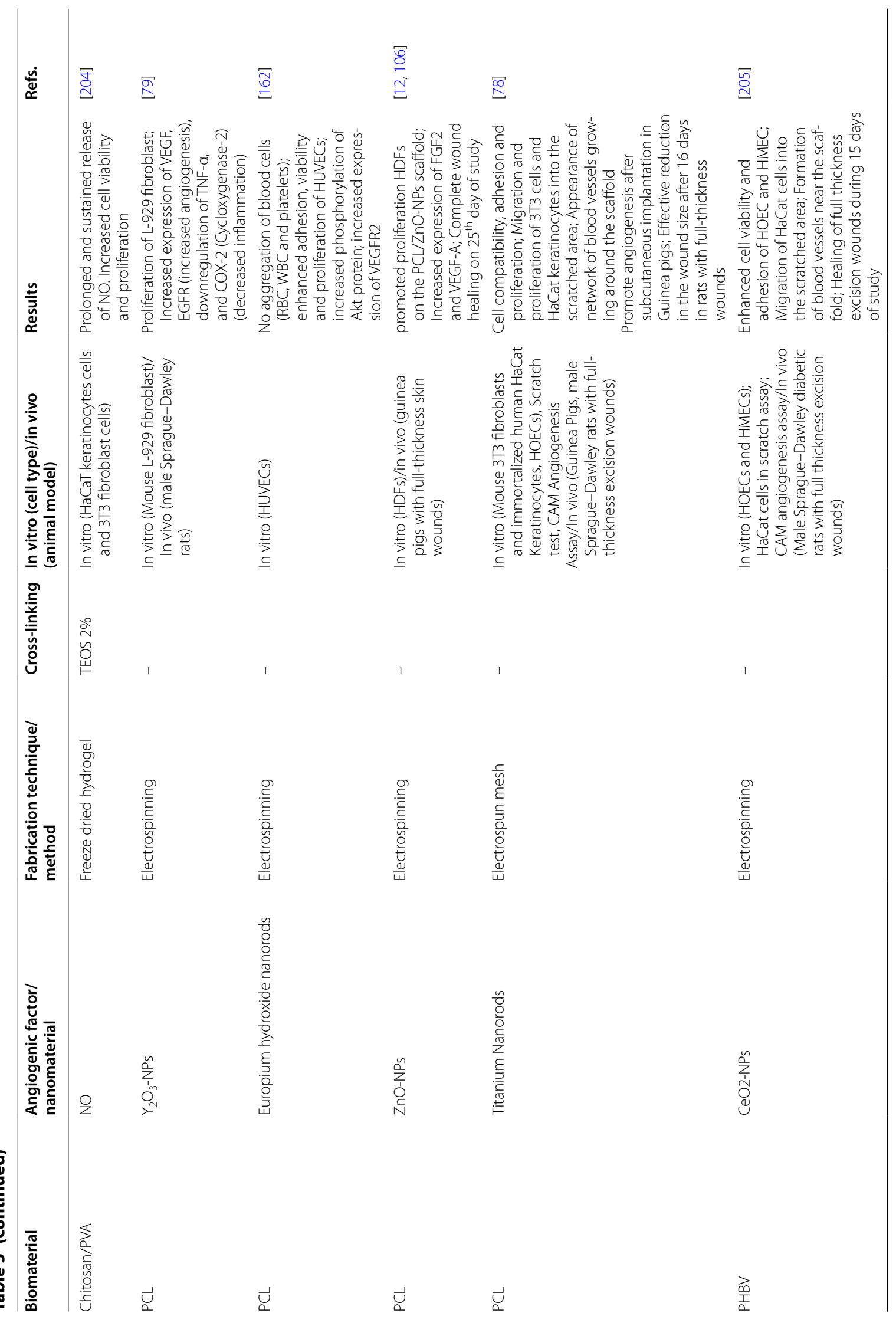




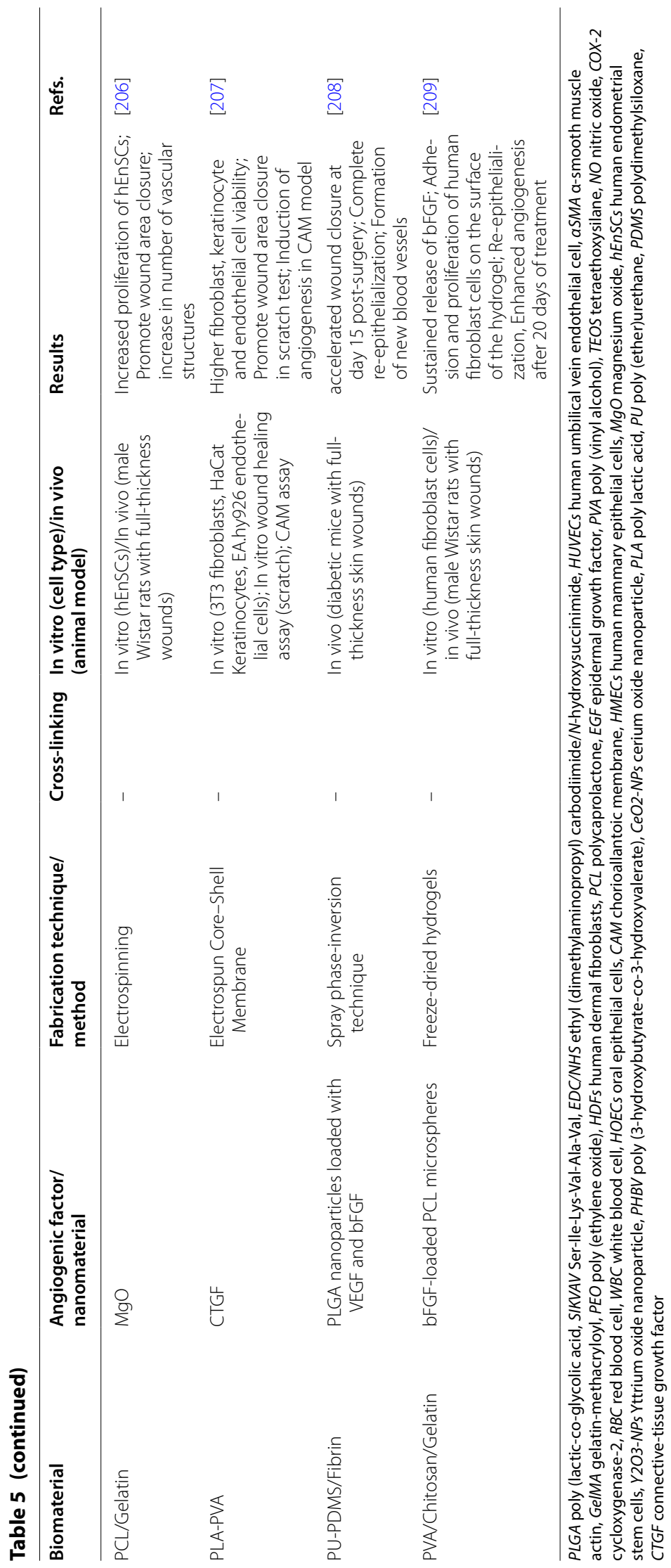




\section{Conclusion}

Skin as an integral organ is the body's first barrier against external pathogens. Any serious damage to the skin could have an impact on human health and quality of life. The management of the pathological conditions of this organ seems to be a critical issue in order to reduce the economic pressure on the medical system and patients. In recent decades, different approaches have been developed to improve the rate and quality of chronic wound healing. What is evident is the essential role of angiogenesis in the regeneration of damaged skin. Common approaches for improving angiogenesis are based on cell, protein and gene delivery systems. Recent progress in nanobiotechnology has significantly improved potential applications in delivery systems. Developed methods in material science and tissue engineering provide an opportunity to use angiogenic nanobiomaterials in the design of engineering structures to provide complex, sustained release systems. In this paper, we reviewed the different uses of angiogenic nanobiomaterials in chronic wound healing and skin tissue engineering applications based on previous studies.

As mentioned above, the generation of a functional vascular network is one of the major challenges in the regeneration of damaged skin. For this purpose, the quality of the regenerated vascular network is more important than quantity. In other words, functional blood perfusion over the vascular network is the criterion, not just the number of regenerated vessels. The importance of the organization and maturation of the vascular structure is therefore clear. On the other hand, over-stimulating angiogenesis leads to the generation of many unorganized vessels with poor blood perfusion and inefficient performance. The organization of vascular structures is not only a factor that determines the quality of the regenerated tissue, but it seems to be a basic principle. Incorporation of bioactive molecules and nanobiomaterials with angiogenic properties is a growing strategy that is highly useful for improving tissue regeneration by improving angiogenesis and vascularization, but achieving tissue with normal and functional vascular structures remains a challenge.

\footnotetext{
Abbreviations

HUVECs: Human umblical vein endothelial cells; CAM: Chorioallantoic membrane; hBMSCs: Human bone marrow stem cells; HUCPVCs: Human umbilical cord perivascular cells; HAECs: Human amniotic epithelial cells; PLGA: Poly (lactic-co-glycolic acid); SIKVAV: Ser-Ile-Lys-Val-Ala-Val; EDC/NHS: N-ethyl$N^{\prime}$ - (3- (dimethylamino)propyl) carbodiimide/N-hydroxysuccinimide; aSMA: a-Smooth muscle actin; GelMA: Gelatin-methacryloyl; PEO: Poly (ethylene oxide); HDFs: Human dermal fibroblasts; PCL: Polycaprolactone; EGF: Epidermal growth factor; PVA: Poly (vinyl alcohol); TEOS: Tetraethoxysilane; NO: Nitric oxide; COX-2: Cycloxygenase-2; RBC: Red blood cell;WBC: White blood cell; HOECs: Oral epithelial cells; CAM: Chorioallantoic membrane; HMECs: Human mammary epithelial cells; MgO: Magnesium oxide; hEnSCs: Human endometrial stem cells; Y2O3-NPs: Yttrium oxide nanoparticle; PHBV: Poly (3-hydroxybutyrate-co-3-hydroxyvalerate); CeO2-NPs: Cerium oxide nanoparticle; PLA:
}

Poly lactic acid; PU: Poly (ether)urethane; PDMS: Polydimethylsiloxane; CTGF: Connective-tissue growth factor.

\section{Acknowledgements}

Not applicable.

\section{Authors' contributions}

$\mathrm{HN}$ wrote the main draft and is the corresponding author. RA and AN investigated the mechanical and physicochemical properties of the scaffolds and helped in paper writing and editing, MK helped in paper writing, editing and research. $M B, K A$, SS and ZA helped in writing and final editing. All authors read and approved the final manuscript.

\section{Funding}

This paper was not financially supported.

\section{Availability of data and materials}

Not applicable

\section{Ethics approval and consent to participate}

Not applicable.

\section{Consent for publication}

Not applicable.

\section{Competing interests}

The authors declare that they have no competing interests.

\section{Author details}

${ }^{1}$ Department of Tissue Engineering and Applied Cell Sciences, School of Advanced Technologies, Shahrekord University of Medical Sciences, Shahrekord, Iran. ${ }^{2}$ Department of Virology, Iran University of Medical Sciences, Tehran, Iran. ${ }^{3}$ School of Mechanical Engineering, College of Engineering, University of Tehran, Tehran, Iran. ${ }^{4}$ Department of Materials Science and Engineering, Golpayegan University of Technology, Golpayegan, Iran. ${ }^{5}$ Department of Molecular Medicine, School of Advanced Technologies, Shahrekord University of Medical Sciences, Shahrekord, Iran. ${ }^{6}$ Department of Medical Biotechnology, School of Advanced Technologies, Shahrekord University of Medical Sciences, Shahrekord, Iran. ${ }^{7}$ Endometrium and Endometriosis Research Center, Hamadan University of Medical Sciences, Hamadan, Iran. ${ }^{8}$ Department of Anatomical Sciences, School of Medicine, Hamadan University of Medical Sciences, Hamadan, Iran.

Received: 27 October 2020 Accepted: 12 December 2020

Published online: 04 January 2021

\section{References}

1. Olsson M, Järbrink K, Divakar U, Bajpai R, Upton Z, Schmidtchen A, et al. The humanistic and economic burden of chronic wounds: a systematic review. Wound Repair Regener. 2019;27(1):114-25.

2. Zhao $R$, Liang $H$, Clarke $E$, Jackson C, Xue M. Inflammation in chronic wounds. Int J Mol Sci. 2016;17(12):2085.

3. Las Heras K, Igartua M, Santos-Vizcaino E, Hernandez RM. Chronic wounds: current status, available strategies and emerging therapeutic solutions. J Control Release. 2020:328:532-50.

4. Cheng Q, Gibb M, Graves N, Finlayson K, Pacella RE. Cost-effectiveness analysis of guideline-based optimal care for venous leg ulcers in Australia. BMC Health Serv Res. 2018;18(1):421.

5. Weller CD, Team V Sussman G. First-line interactive wound dressing update: a comprehensive review of the evidence. Front Pharmacol. 2020;11:155.

6. Boyce ST, Kagan RJ, Greenhalgh DG, Warner P, Yakuboff KP, Palmieri $\mathrm{T}$, et al. Cultured skin substitutes reduce requirements for harvesting of skin autograft for closure of excised, full-thickness burns. JTrauma Acute Care Surg. 2006;60(4):821-9.

7. Ramsey ML, Patel BC. Full thickness skin grafts. 2019.

8. Velnar T, Bailey T, Smrkolj V. The wound healing process: an overview of the cellular and molecular mechanisms. J Int Med Res. 2009;37(5):1528-42. 
9. Enoch S, Leaper DJ. Basic science of wound healing. Surgery (Oxford). 2008;26(2):31-7.

10. Liang J, Cui L, Li J, Guan S, Zhang K, Li J. Aloe vera: a medicinal plant used in skin wound healing. Tissue Engineering Part B: Reviews; 2020.

11. Folkman J. Angiogenesis. Annu Rev Med. 2006;57:1-18.

12. Augustine R, Dominic EA, Reju I, Kaimal B, Kalarikkal N, Thomas S. Investigation of angiogenesis and its mechanism using zinc oxide nanoparticle-loaded electrospun tissue engineering scaffolds. Rsc Adv. 2014:4(93):51528-36.

13. Naderi $\mathrm{H}$, Matin MM, Bahrami AR. Critical issues in tissue engineering: biomaterials, cell sources, angiogenesis, and drug delivery systems. J Biomater Appl. 2011;26(4):383-417.

14. Liu M, Liu T, Chen X, Yang J, Deng J, He W, et al. Nano-silver-incorporated biomimetic polydopamine coating on a thermoplastic polyurethane porous nanocomposite as an efficient antibacterial wound dressing. J Nanobiotechnol. 2018;16(1):1-19.

15. Wang W, Lu K-j, Yu C-h, Huang Q-I, Du Y-Z. Nano-drug delivery systems in wound treatment and skin regeneration. J Nanobiotechnol. 2019;17(1):82

16. Bramhill J, Ross S, Ross G. Bioactive nanocomposites for tissue repair and regeneration: a review. International Journal of Environmental Research and Public Health. 2017;14(1):66.

17. Bauer SM, Bauer RJ, Velazquez OC. Angiogenesis, vasculogenesis, and induction of healing in chronic wounds. Vasc Endovasc Surg. 2005;39(4):293-306

18. Caley MP, Martins VL, O'Toole EA. Metalloproteinases and wound healing. Adv Wound Care. 2015;4(4):225-34.

19. Blanco R, Gerhardt H. VEGF and Notch in tip and stalk cell selection. Cold Spring Harbor Persp Med. 2013;3(1):a006569.

20. Bentley K, Franco CA, Philippides A, Blanco R, Dierkes M, Gebala V, et al. The role of differential VE-cadherin dynamics in cell rearrangement during angiogenesis. Nat Cell Biol. 2014;16(4):309-21.

21. Ribatti $D$, Nico B, Crivellato E. The role of pericytes in angiogenesis. Int J Dev Biol. 2011;55(3):261-8.

22. Bayless KJ, Johnson GA. Role of the cytoskeleton in formation and maintenance of angiogenic sprouts. J Vasc Res. 2011;48(5):369-85.

23. Risau W. Mechanisms of angiogenesis. Nature. 1997;386(6626):671-4.

24. Germain S, Monnot C, Muller L, Eichmann A. Hypoxia-driven angiogenesis: role of tip cells and extracellular matrix scaffolding. Curr Opin Hematol. 2010;17(3):245-51

25. Tomanek RJ, Holifield JS, Reiter RS, Sandra A, Lin JJC. Role of VEGF family members and receptors in coronary vessel formation. Dev Dyn. 2002;225(3):233-40

26. Peach CJ, Mignone VW, Arruda MA, Alcobia DC, Hill SJ, Kilpatrick LE, et al. Molecular pharmacology of VEGF-A isoforms: binding and signalling at VEGFR2. Int J Mol Sci. 2018;19(4):1264.

27. Arcondéguy T, Lacazette E, Millevoi S, Prats H, Touriol C. VEGF-A mRNA processing, stability and translation: a paradigm for intricate regulation of gene expression at the post-transcriptional level. Nucleic Acids Res. 2013;41(17):7997-8010.

28. Koch S, Tugues S, Li X, Gualandi L, Claesson-Welsh L. Signal transduction by vascular endothelial growth factor receptors. Biochem J. 2011:437(2):169-83.

29. Meyer RD, Rahimi N. Comparative structure-function analysis of VEGFR-1 and VEGFR-2: what have we learned from chimeric systems? Ann N Y Acad Sci. 2003;995(1):200-7.

30. Boulton ME, Cai J, Grant MB, Zhang Y. Y-Secretase regulates VEGFR-1 signalling in vascular endothelium and RPE. Recent advances in retinal degeneration. Berlin: Springer; 2008. p. 313-9.

31. Gao J, Hu H, Wang X. Clinically relevant concentrations of lidocaine inhibit tumor angiogenesis through suppressing VEGF/NEGFR2 signaling. Cancer Chemother Pharmacol. 2019;83(6):1007-15.

32. Bansode RR, Leung T, Randolph P, Williams LL, Ahmedna M. Cinnamon extract inhibits angiogenesis in zebrafish and human endothelial cells by suppressing VEGFR 1, VEGFR 2, and PKC-mediated MAP kinase. Food Sci Nutr. 2013;1(1):74-82.

33. Niimi Y, Mochida S, Matsui A, Inao M, Fujiwara K. PKC-and MAPKindependent upregulation of VEGF receptor expressions in human umbilical venous endothelial cells following VEGF stimulation. Hepatol Res. 2001;21(3):261-7.
34. Zhou Y, Guan X, Yu M, Wang X, Zhu W, Wang C, et al. Angiogenic/osteogenic response of BMMSCs on bone-derived scaffold: effect of hypoxia and role of PI3K/Akt-mediated VEGF-VEGFR pathway. Biotechnol J. 2014;9(7):944-53.

35. Park H, Choi S-H, Kong M-J, Kang T-C. Dysfunction of 67-kDa laminin receptor disrupts BBB integrity via impaired dystrophin/AQP4 complex and p38 MAPKNEGF activation following status epilepticus. Front Cell Neurosci. 2019;13:236.

36. Sainz-Jaspeado M, Claesson-Welsh L. Cytokines regulating lymphangiogenesis. Curr Opin Immunol. 2018;53:58-63.

37. Sun S, Gong F, Liu P, Miao Q. Metformin combined with quercetin synergistically repressed prostate cancer cells via inhibition of VEGF/PI3K Akt signaling pathway. Gene. 2018;664:50-7.

38. Sun W, Wang X, Li J, You C, Lu P, Feng H, et al. MicroRNA-181a promotes angiogenesis in colorectal cancer by targeting SRCIN1 to promote the SRCNEGF signaling pathway. Cell Death Dis. 2018;9(4):1-13.

39. Mehta RR, Yamada T, Taylor BN, Christov K, King ML, Majumdar D, et al. A cell penetrating peptide derived from azurin inhibits angiogenesis and tumor growth by inhibiting phosphorylation of VEGFR-2. FAK and Akt. Angiogenesis. 2011;14(3):355-69.

40. Zhao D, Xue C, Lin S, Shi S, Li Q, Liu M, et al. Notch signaling pathway regulates angiogenesis via endothelial cell in 3D co-culture model. J Cell Physiol. 2017;232(6):1548-58.

41. Fagiani E, Christofori G. Angiopoietins in angiogenesis. Cancer Lett. 2013;328(1):18-26.

42. Hakanpaa L, Sipila T, Leppanen VM, Gautam P, Nurmi H, Jacquemet G, et al. Endothelial destabilization by angiopoietin-2 via integrin beta1 activation. Nat Commun. 2015;6:5962.

43. Saharinen $P$, Eklund $L$, Alitalo K. Therapeutic targeting of the angiopoietin-TIE pathway. Nat Rev Drug Discov. 2017;16(9):635.

44. Ikushima YM, Arai F, Nakamura Y, Hosokawa K, Kubota Y, Hirashima M, et al. Enhanced Angpt1/Tie2 signaling affects the differentiation and long-term repopulation ability of hematopoietic stem cells. Biochem Biophys Res Commun. 2013;430(1):20-5.

45. Lamont RE, Vu W, Carter AD, Serluca FC, MacRae CA, Childs SJ. Hedgehog signaling via angiopoietin1 is required for developmental vascular stability. Mech Dev. 2010;127(3-4):159-68.

46. Yuan HT, Khankin EV, Karumanchi SA, Parikh SM. Angiopoietin 2 is a partial agonist/antagonist of Tie2 signaling in the endothelium. Mol Cell Biol. 2009;29(8):2011-22.

47. Felcht M, Luck R, Schering A, Seidel P, Srivastava K, Hu J, et al. Angiopoietin-2 differentially regulates angiogenesis through TIE2 and integrin signaling. J Clin Investig. 2012;122(6):1991-2005.

48. Lukasz A, Kümpers P, David S. Role of angiopoietin/tie2 in critical illness: promising biomarker, disease mediator, and therapeutic target? Scientifica. 2012:2012:15

49. Honma M, Higuchi O, Shirakata M, Yasuda T, Shibuya H, lemura Si, et al. Dok-3 sequesters Grb2 and inhibits the Ras-Erk pathway downstream of protein-tyrosine kinases. Genes Cells. 2006;11(2):143-51.

50. Zeng H, Jiang $Y$, Tang H, Ren Z, Zeng G, Yang Z. Abnormal phosphorylation of Tie2/Akt/eNOS signaling pathway and decreased number or function of circulating endothelial progenitor cells in prehypertensive premenopausal women with diabetes mellitus. BMC Endocr Disord. 2016;16(1):13.

51. Zhang J, Liu Z, Li Y, You Q, Yang J, Jin Y, et al. FGF2: a key regulator augmenting tendon-to-bone healing and cartilage repair. Regener Med. 2020.

52. Kim MH. Flavonoids inhibit VEGF/bFGF-induced angiogenesis in vitro by inhibiting the matrix-degrading proteases. J Cell Biochem. 2003:89(3):529-38.

53. Ribatti D, Presta M. The role of fibroblast growth factor- 2 in the vascularization of the chick embryo chorioallantoic membrane. J Cell Mol Med. 2002;6(3):439-46.

54. Parenti A, Morbidelli L, Ledda F, Granger HJ, Ziche M. The bradykinin/ B1 receptor promotes angiogenesis by up-regulation of endogenous FGF-2 in endothelium via the nitric oxide synthase pathway. FASEB J. 2001;15(8):1487-9.

55. Stavri GT, Zachary IC, Baskerville PA, Martin JF, Erusalimsky JD. Basic fibroblast growth factor upregulates the expression of vascular endothelial growth factor in vascular smooth muscle cells: synergistic interaction with hypoxia. Circulation. 1995;92(1):11-4. 
56. Asahara T, Bauters C, Zheng LP, Takeshita S, Bunting S, Ferrara N, et al. Synergistic effect of vascular endothelial growth factor and basic fibroblast growth factor on angiogenesis in vivo. Circulation. 1995;92(9):365-71.

57. Doi K, Ikeda T, Marui A, Kushibiki T, Arai Y, Hirose K, et al. Enhanced angiogenesis by gelatin hydrogels incorporating basic fibroblast growth factor in rabbit model of hind limb ischemia. Heart Vessels. 2007;22 (2):104-8.

58. Yoo Y, Hyun H, Yoon S-J, Kim SY, Lee D-W, Um S, et al. Visible light-cured glycol chitosan hydrogel dressing containing endothelial growth factor and basic fibroblast growth factor accelerates wound healing in vivo. J Ind Eng Chem. 2018;67:365-72.

59. Ding Y, Zhao A, Liu T, Wang Y, Gao Y, Li J, et al. An injectable nanocomposite hydrogel for potential application of vascularization and tissue repair. Ann Biomed Eng. 2020;48(5):1511-23.

60. He D, Zhao A-S, Su H, Zhang Y, Wang Y-N, Luo D, et al. An injectable scaffold based on temperature-responsive hydrogel and factor-loaded nanoparticles for application in vascularization in tissue engineering. J Biomed Mater Res, Part A. 2019;107(10):2123-34.

61. Lee K, Silva EA, Mooney DJ. Growth factor delivery-based tissue engineering: general approaches and a review of recent developments. J R Soc Interface. 2011;8(55):153-70.

62. Kastrup J. Gene therapy and angiogenesis in patients with coronary artery disease. Exp Rev Cardiovasc Ther. 2010;8(8):1127-38.

63. Mi B, Chen L, Xiong Y, Yan C, Xue H, Panayi AC, et al. Saliva exosomesderived UBE2O mRNA promotes angiogenesis in cutaneous wounds by targeting SMAD6. Journal of Nanobiotechnology. 2020;18:1-14.

64. Icli B, Wu W, Ozdemir D, Li H, Haemmig S, Liu X, et al. MicroRNA-135a-3p regulates angiogenesis and tissue repair by targeting $\mathrm{p} 38$ signaling in endothelial cells. FASEB J. 2019;33(4):5599-614.

65. Sorg H, Krueger C, Schulz T, Menger MD, Schmitz F, Vollmar B. Effects of erythropoietin in skin wound healing are dose related. FASEB J. 2009;23(9):3049-58.

66. Wu Y, Chen L, Scott PG, Tredget EE. Mesenchymal stem cells enhance wound healing through differentiation and angiogenesis. Stem Cells. 2007;25(10):2648-59.

67. Martin CR. Nanomaterials: a membrane-based synthetic approach. Science. 1994;266(5193):1961-6.

68. Aguilar Z. Nanomaterials for medical applications. Berlin: Newnes; 2012.

69. Tocco I, Zavan B, Bassetto F, Vindigni V. Nanotechnology-based therapies for skin wound regeneration. J Nanomater. 2012;2012:714134.

70. Shahzadi L, Chaudhry AA, Aleem AR, Malik MH, ljaz K, Akhtar H, et al. Development of K-doped $\mathrm{ZnO}$ nanoparticles encapsulated crosslinked chitosan based new membranes to stimulate angiogenesis in tissue engineered skin grafts. Int J Biol Macromol. 2018;120:721-8.

71. Nelson CE, Kim AJ, Adolph EJ, Gupta MK, Yu F, Hocking KM, et al. Tunable delivery of siRNA from a biodegradable scaffold to promote angiogenesis in vivo. Adv Mater. 2014;26(4):607-14.

72. Hadjizadeh A, Ghasemkhah F, Ghasemzaie N. Polymeric scaffold based gene delivery strategies to improve angiogenesis in tissue engineering: a review. Polym Rev. 2017;57(3):505-56.

73. Zaman HU, Islam JMM, Khan MA, Khan RA. Physico-mechanical properties of wound dressing material and its biomedical application. J Mech Behav Biomed Mater. 2011;4(7):1369-75.

74. Lima LL, Taketa TB, Beppu MM, Sousa IMdO, Foglio MA, Moraes ÂM. Coated electrospun bioactive wound dressings: mechanical properties and ability to control lesion microenvironment. Mater Sci Eng C. 2019;100:493-504.

75. Zahouani H, Pailler-Mattei C, Sohm B, Vargiolu R, Cenizo V, Debret R. Characterization of the mechanical properties of a dermal equivalent compared with human skin in vivo by indentation and static friction tests. Skin Res Technol. 2009;15(1):68-76.

76. Luebberding S, Krueger N, Kerscher M. Mechanical properties of human skin in vivo: a comparative evaluation in 300 men and women. Skin Res Technol. 2014;20(2):127-35.

77. Lancerotto L, Orgill DP. Mechanoregulation of Angiogenesis in Wound Healing. Adv Wound Care. 2014;3(10):626-34

78. Rehman SR, Augustine R, Zahid AA, Ahmed R, Tariq M, Hasan A. Reduced graphene oxide incorporated GelMA hydrogel promotes angiogenesis for wound healing applications. Int J Nanomed. 2019;14:9603
79. Augustine R, Dalvi YB, Nath VY, Varghese R, Raghuveeran V, Hasan A, et al. Yttrium oxide nanoparticle loaded scaffolds with enhanced cell adhesion and vascularization for tissue engineering applications. Mater Sci Eng, C. 2019;103:109801

80. Vázquez N, Sánchez-Arévalo F, Maciel-Cerda A, Garnica-Palafox I, Ontiveros-Tlachi R, Chaires-Rosas C, et al. Influence of the PLGA/gelatin ratio on the physical, chemical and biological properties of electrospun scaffolds for wound dressings. Biomed Mater. 2019;14(4):045006.

81. Jafari A, Amirsadeghi A, Hassanajili S, Azarpira N. Bioactive antibacterial bilayer PCL/gelatin nanofibrous scaffold promotes full-thickness wound healing. Int J Pharm. 2020;583:119413.

82. Khil M-S, Cha D-I, Kim H-Y, Kim I-S, Bhattarai N. Electrospun nanofibrous polyurethane membrane as wound dressing. J Biomed Mater Res B Appl Biomater. 2003;67B(2):675-9.

83. Karuppuswamy P, Venugopal JR, Navaneethan B, Laiva AL, Sridhar S, Ramakrishna S. Functionalized hybrid nanofibers to mimic native ECM for tissue engineering applications. Appl Surf Sci. 2014;322:162-8.

84. Freyman TM, Yannas IV, Gibson L. Cellular materials as porous scaffolds for tissue engineering. Prog Mater Sci. 2001;46(3):273-82.

85. Miguel SP, Ribeiro MP, Coutinho P, Correia IJ. Electrospun polycaprolactone/aloe vera_chitosan nanofibrous asymmetric membranes aimed for wound healing applications. Polymers. 2017;9:5.

86. Sinha N, Yeow J-W. Carbon nanotubes for biomedical applications. IEEE Trans Nanobiosci. 2005;4(2):180-95.

87. Boccaccini AR, Erol M, Stark WJ, Mohn D, Hong Z, Mano JF. Polymer/ bioactive glass nanocomposites for biomedical applications: a review. Compos Sci Technol. 2010;70(13):1764-76.

88. Guo S, Zhu X, Li M, Shi L, Ong JLT, Jańczewski D, et al. Parallel control over surface charge and wettability using polyelectrolyte architecture: effect on protein adsorption and cell adhesion. ACS Appl Mater Interfaces. 2016;8(44):30552-63.

89. Neto A, Levkin P, Mano JF. Patterned superhydrophobic surfaces to process and characterize biomaterials and 3D cell culture. Mater Horizons. 2018:5:12.

90. Kumbar SG, Nukavarapu SP, James R, Nair LS, Laurencin CT. Electrospun poly (lactic acid-co-glycolic acid) scaffolds for skin tissue engineering. Biomaterials. 2008;29(30):4100-7.

91. Miguel SP, Moreira AF, Correia IJ. Chitosan based-asymmetric membranes for wound healing: a review. Int J Biol Macromol. 2019:127:460-75.

92. Lin W-C, Lien C-C, Yeh H-J, Yu C-M, Hsu S-h. Bacterial cellulose and bacterial cellulose-chitosan membranes for wound dressing applications. Carbohyd Polym. 2013;94 (1):603-11.

93. Morgado PI, Aguiar-Ricardo A, Correia IJ. Asymmetric membranes as ideal wound dressings: an overview on production methods, structure, properties and performance relationship. J Membr Sci. 2015:490:139-51.

94. Chen Y, Yan L, Yuan T, Zhang Q, Fan H. Asymmetric polyurethane membrane with in situ-generated nano-TiO2 as wound dressing. J Appl Polym Sci. 2011;119(3):1532-41.

95. Bishop A. Role of oxygen in wound healing. J Wound Care. 2008;17(9):399-402.

96. Elsner JJ, Shefy-Peleg A, Zilberman M. Novel biodegradable composite wound dressings with controlled release of antibiotics: microstructure, mechanical and physical properties. J Biomed Mater Res B Appl Biomater. 2010;93B(2):425-35.

97. Elsner JJ, Egozi D, Ullmann Y, Berdicevsky I, Shefy-Peleg A, Zilberman M. Novel biodegradable composite wound dressings with controlled release of antibiotics: results in a guinea pig burn model. Burns. 2011;37(5):896-904.

98. de Souza JF, da Silva Pontes K, Alves TFR, Torqueti de Barros C, Amaral VA, de Moura Crescencio KM, et al. Structural comparison, physicochemical properties, and in vitro release profile of curcumin-loaded lyotropic liquid crystalline nanoparticle: Influence of hydrotrope as interface stabilizers. J Mol Liquids. 2020;306:112861.

99. Séon-Lutz M, Couffin A-C, Vignoud S, Schlatter G, Hébraud A. Electrospinning in water and in situ crosslinking of hyaluronic acid/cyclodextrin nanofibers: towards wound dressing with controlled drug release. Carbohyd Polym. 2019;207:276-87.

100. Wan WK, Yang L, Padavan DT. Use of degradable and nondegradable nanomaterials for controlled release. Nanomedicine. 2007;2(4):483-509. 
101. Xiao J, Zhu Y, Huddleston S, Li P, Xiao B, Farha OK, et al. Copper metalorganic framework nanoparticles stabilized with folic acid improve wound healing in diabetes. ACS Nano. 2018;12(2):1023-32.

102. Ponche A, Ploux L, Anselme K. Protein/material interfaces: investigation on model surfaces. J Adhes Sci Technol. 2010;24(13-14):2141-64.

103. Cai K, Bossert J, Jandt KD. Does the nanometre scale topography of titanium influence protein adsorption and cell proliferation? Colloids Surf B. 2006;49(2):136-44.

104. Awadhiya A, Tyeb S, Rathore K, Verma V. Agarose bioplastic-based drug delivery system for surgical and wound dressings. Eng Life Sci. 2017;17(2):204-14.

105. Barui AK, Nethi SK, Haque S, Basuthakur P, Patra CR. Recent development of metal nanoparticles for angiogenesis study and their therapeutic applications. ACS Appl Bio Mater. 2019.

106. Augustine R, Dominic EA, Reju I, Kaimal B, Kalarikkal N, Thomas S. Electrospun polycaprolactone membranes incorporated with $\mathrm{ZnO}$ nanoparticles as skin substitutes with enhanced fibroblast proliferation and wound healing. Rsc Adv. 2014;4(47):24777-85.

107. Das S, Singh S, Dowding JM, Oommen S, Kumar A, Sayle TX, et al. The induction of angiogenesis by cerium oxide nanoparticles through the modulation of oxygen in intracellular environments. Biomaterials. 2012;33(31):7746-55.

108. Das S, Dowding JM, Klump KE, McGinnis JF, SelfW, Seal S. Cerium oxide nanoparticles: applications and prospects in nanomedicine. Nanomedicine. 2013;8(9):1483-508.

109. Chigurupati S, Mughal MR, Okun E, Das S, Kumar A, McCaffery M, et al. Effects of cerium oxide nanoparticles on the growth of keratinocytes, fibroblasts and vascular endothelial cells in cutaneous wound healing Biomaterials. 2013;34(9):2194-201.

110. Hao D, Zhang G, Gong Y, Ma Z. Development and biological evaluation of cerium oxide loaded polycaprolactone dressing on cutaneous wound healing in nursing care. Mater Lett. 2020;265:127401.

111. Cui L, Liang J, Liu H, Zhang K, Li J. Nanomaterials for angiogenesis in skin tissue engineering. Tissue Eng Part B Rev. 2020;26(3):203-16.

112. Lau P, Bidin N, Islam S, Shukri WNBWM, Zakaria N, Musa N, et al. Influence of gold nanoparticles on wound healing treatment in rat model: Photobiomodulation therapy. Lasers Surg Med. 2017;49(4):380-6.

113. Kim JE, Lee J, Jang M, Kwak MH, Go J, Kho EK, et al. Accelerated healing of cutaneous wounds using phytochemically stabilized gold nanoparticle deposited hydrocolloid membranes. Biomater Sci. 2015;3(3):509-19.

114. Chen Y, Wu Y, Gao J, Zhang Z, Wang L, Chen X, et al. Transdermal vascular endothelial growth factor delivery with surface engineered gold nanoparticles. ACS Appl Mater Interfaces. 2017;9(6):5173-80.

115. Carvalho SM, Moreira CD, Oliveira ACX, Oliveira AA, Lemos EM, Pereira MM. Bioactive glass nanoparticles for periodontal regeneration and applications in dentistry. Nanobiomaterials in clinical dentistry. New York: Elsevier; 2019. p. 351-83.

116. Hench LL. The story of Bioglass ${ }^{\circledR}$. J Mater Sci - Mater Med. 2006;17(11):967-78.

117. Wu T, Cheng N, Xu C, Sun W, Yu C, Shi B. The effect of mesoporous bioglass on osteogenesis and adipogenesis of osteoporotic BMSCs. J Biomed Mater Res, Part A. 2016;104(12):3004-14.

118. Westhauser F, Widholz B, Nawaz Q, Tsitlakidis S, Hagmann S, Moghaddam A, et al. Favorable angiogenic properties of the borosilicate bioactive glass 0106-B1 result in enhanced in vivo osteoid formation compared to 45S5 Bioglass. Biomater Sci. 2019;7(12):5161-76.

119. Kargozar S, Baino F, Hamzehlou S, Hill RG, Mozafari M. Bioactive glasses: sprouting angiogenesis in tissue engineering. Trends Biotechnol. 2018;36(4):430-44.

120. Gargiulo N, Cusano AM, Causa F, Caputo D, Netti PA. Silver-containing mesoporous bioactive glass with improved antibacterial properties. J Mater Sci Mater Med. 2013;24(9):2129-35.

121. Wang $X, L i X$, Ito A, Sogo Y. Synthesis and characterization of hierarchically macroporous and mesoporous $\mathrm{CaO}-\mathrm{MO}-\mathrm{SiO} 2-\mathrm{P} 2 \mathrm{O} 5(\mathrm{M}=\mathrm{Mg}, \mathrm{Zn}$ Sr) bioactive glass scaffolds. Acta Biomater. 2011;7(10):3638-44.

122. Bari A, Bloise N, Fiorilli S, Novajra G, Vallet-Regí M, Bruni G, et al. Coppercontaining mesoporous bioactive glass nanoparticles as multifunctional agent for bone regeneration. Acta Biomater. 2017;55:493-504.

123. Kaya S, Cresswell M, Boccaccini AR. Mesoporous silica-based bioactive glasses for antibiotic-free antibacterial applications. Mater Sci Eng, C. 2018:83:99-107.
124. Saghiri MA, Asatourian A, Orangi J, Sorenson CM, Sheibani N. Functional role of inorganic trace elements in angiogenesis-part II: $\mathrm{Cr}, \mathrm{Si}, \mathrm{Zn}, \mathrm{Cu}$, and S. Critic Rev Oncol Hematol. 2015:96(1):143-55.

125. Wong KK, Cheung SO, Huang L, Niu J, Tao C, Ho CM, et al. Further evidence of the anti-inflammatory effects of silver nanoparticles. ChemMedChem. 2009;4(7):1129-35.

126. Nokhasteh S, Sadeghi-avalshahr A, Molavi AM, Khorsand-Ghayeni $M$, Naderi-Meshkin H. Effect of bioactive glass nanoparticles on biological properties of PLGA/collagen scaffold. Progress Biomater. 2018;7(2):111-9.

127. Weng L, Boda SK, Teusink MJ, Shuler FD, Li X, Xie J. Binary doping of strontium and copper enhancing osteogenesis and angiogenesis of bioactive glass nanofibers while suppressing osteoclast activity. ACS Appl Mater Interfaces. 2017;9(29):24484-96.

128. Zheng K, Boccaccini AR. Sol-gel processing of bioactive glass nanoparticles: a review. Adv Coll Interface Sci. 2017:249:363-73.

129. Hoppe A, Güldal NS, Boccaccini AR. A review of the biological response to ionic dissolution products from bioactive glasses and glass-ceramics. Biomaterials. 2011;32(11):2757-74.

130. Jung S, Day D, Day T, Stoecker W, Taylor P. Treatment of non-healing diabetic venous stasis ulcers with bioactive glass nanofibers. Wound Repair Regener. 2011;19:2.

131. Lin Y, Brown RF, Jung SB, Day DE. Angiogenic effects of borate glass microfibers in a rodent model. J Biomed Mater Res, Part A 2014;102(12):4491-9.

132. Li H, Chang J. Stimulation of proangiogenesis by calcium silicate bioactive ceramic. Acta Biomater. 2013:9(2):5379-89.

133. Durand LAH, Vargas GE, Romero NM, Vera-Mesones R, Porto-López JM, Boccaccini AR, et al. Angiogenic effects of ionic dissolution products released from a boron-doped $45 S 5$ bioactive glass. J Mater Chem B. 2015:3(6):1142-8.

134. Wang H, Zhao S, Zhou J, Shen Y, Huang W, Zhang C, et al. Evaluation of borate bioactive glass scaffolds as a controlled delivery system for copper ions in stimulating osteogenesis and angiogenesis in bone healing. J Mater Chem B. 2014;2(48):8547-57.

135. Kargozar S, Lotfibakhshaiesh N, Ai J, Mozafari M, Milan PB, Hamzehlou S, et al. Strontium-and cobalt-substituted bioactive glasses seeded with human umbilical cord perivascular cells to promote bone regeneration via enhanced osteogenic and angiogenic activities. Acta Biomater. 2017:58:502-14.

136. Detsch R, Stoor P, Grünewald A, Roether JA, Lindfors NC, Boccaccini AR. Increase in VEGF secretion from human fibroblast cells by bioactive glass S53P4 to stimulate angiogenesis in bone. J Biomed Mater Res, Part A. 2014;102(11):4055-61.

137. Zhai W, Lu H, Chen L, Lin X, Huang Y, Dai K, et al. Silicate bioceramics induce angiogenesis during bone regeneration. Acta Biomater. 2012;8(1):341-9.

138. Shi M, Xia L, Chen Z, Lv F, Zhu H, Wei F, et al. Europium-doped mesoporous silica nanosphere as an immune-modulating osteogenesis/angiogenesis agent. Biomaterials. 2017;144:176-87.

139. Miguez-Pacheco V, De Ligny D, Schmidt J, Detsch R, Boccaccini A. Development and characterization of niobium-releasing silicate bioactive glasses for tissue engineering applications. J Eur Ceram Soc. 2018;38(3):871-6.

140. Zhang Y, Cui X, Zhao S, Wang H, Rahaman MN, Liu Z, et al. Evaluation of injectable strontium-containing borate bioactive glass cement with enhanced osteogenic capacity in a critical-sized rabbit femoral condyle defect model. ACS Appl Mater Interfaces. 2015;7(4):2393-403.

141. Baino F, Hamzehlou S, Kargozar S. Bioactive glasses: where are we and where are we going? J Funct Biomater. 2018;9(1):25.

142. Dresselhaus MS, Dresselhaus G, Eklund P, Rao A. Carbon nanotubes. The physics of fullerene-based and fullerene-related materials. Berlin: Springer; 2000. p. 331-79.

143. Wu H-C, Chang X, Liu L, Zhao F, Zhao Y. Chemistry of carbon nanotubes in biomedical applications. J Mater Chem. 2010;20(6):1036-52.

144. Veetil JV, Ye K. Tailored carbon nanotubes for tissue engineering applications. Biotechnol Prog. 2009;25(3):709-21.

145. Masotti A, Miller MR, Celluzzi A, Rose L, Micciulla F, Hadoke PW, et al. Regulation of angiogenesis through the efficient delivery of microRNAs into endothelial cells using polyamine-coated carbon nanotubes. Nanomedicine. 2016:12(6):1511-22. 
146. Liu Z, Feng X, Wang H, Ma J, Liu W, Cui D, et al. Carbon nanotubes as VEGF carriers to improve the early vascularization of porcine small intestinal submucosa in abdominal wall defect repair. Int J Nanomed. 2014;9:1275.

147. Lalwani G, Gopalan A, D'Agati M, Srinivas Sankaran J, Judex S, Qin YX, et al. Porous three-dimensional carbon nanotube scaffolds for tissue engineering. J Biomed Mater Res, Part A. 2015;103(10):3212-25.

148. Unwin PR, Güell AG, Zhang G. Nanoscale electrochemistry of sp2 carbon materials: from graphite and graphene to carbon nanotubes. Acc Chem Res. 2016;49(9):2041-8.

149. Liu Z, Robinson JT, Sun X, Dai H. PEGylated nanographene oxide for delivery of water-insoluble cancer drugs. J Am Chem Soc. 2008;130(33):10876-7.

150. Zhu Z. An overview of carbon nanotubes and graphene for biosensing applications. Nano-micro Lett. 2017;9(3):25

151. Reina G, González-Domínguez JM, Criado A, Vázquez E, Bianco A, Prato M. Promises, facts and challenges for graphene in biomedical applications. Chem Soc Rev. 2017:46(15):4400-16.

152. Shin SR, Li Y-C, Jang HL, Khoshakhlagh P, Akbari M, Nasajpour A, et al. Graphene-based materials for tissue engineering. Adv Drug Deliv Rev. 2016;105:255-74.

153. Lee J, Kim J, Kim S, Min D-H. Biosensors based on graphene oxide and its biomedical application. Adv Drug Deliv Rev. 2016;105:275-87.

154. Santhosh K, Modak MD, Paik P. Graphene oxide for biomedical applications. J Nanomed Res. 2017;5(6):1-6.

155. Norahan MH, Amroon M, Ghahremanzadeh R, Mahmoodi M, Baheirae $\mathrm{N}$. Electroactive graphene oxide-incorporated collagen assisting vascularization for cardiac tissue engineering. J Biomed Mater Res, Part A. 2019;107(1):204-19.

156. Mukherjee S, Sriram P, Barui AK, Nethi SK, Veeriah V, Chatterjee S, et al. Graphene oxides show angiogenic properties. Adv Healthcare Mater. 2015;4(11):1722-32.

157. Chng ELK, Pumera M. The toxicity of graphene oxides: dependence on the oxidative methods used. Chem Eur J. 2013;19(25):8227-35.

158. Qian Y, Song J, Zhao X, Chen W, Ouyang Y, Yuan W, et al. 3D fabrication with integration molding of a graphene oxide/polycaprolactone nanoscaffold for neurite regeneration and angiogenesis. Adv Sci. 2018:5(4):1700499.

159. Nyambat B, Chen C-H, Wong P-C, Chiang C-W, Satapathy MK, Chuang E-Y. Genipin-crosslinked adipose stem cell derived extracellular matrixnano graphene oxide composite sponge for skin tissue engineering. $J$ Mater Chem B. 2018;6(6):979-90.

160. Martinić I, Eliseeva SV, Petoud S. Near-infrared emitting probes for biological imaging: organic fluorophores, quantum dots, fluorescent proteins, lanthanide (III) complexes and nanomaterials. J Lumin. 2017;189:19-43.

161. Patra CR, Bhattacharya R, Patra S, Vlahakis NE, Gabashvili A, Koltypin Y, et al. Pro-angiogenic properties of europium (III) hydroxide nanorods. Adv Mater. 2008;20(4):753-6.

162. Augustine R, Nethi SK, Kalarikkal N, Thomas S, Patra CR. Electrospun polycaprolactone (PCL) scaffolds embedded with europium hydroxide nanorods (EHNs) with enhanced vascularization and cell proliferation for tissue engineering applications. J Mater Chem B. 2017;5(24):4660-72.

163. Staton CA, Reed MWR, Brown NJ. A critical analysis of current in vitro and in vivo angiogenesis assays. Int J Exp Pathol. 2009;90(3):195-221.

164. Groeber F, Holeiter M, Hampel M, Hinderer S, Schenke-Layland K. Skin tissue engineering - in vivo and in vitro applications. Adv Drug Deliv Rev. 2011;63(4-5):352-66.

165. Hartmann CA, Rode H, Kramer B. Acticoat ${ }^{\mathrm{TM}}$ stimulates inflammation, but does not delay healing, in acute full-thickness excisional wounds. International wound journal. 2016;13(6):1344-8.

166. Mohamed A, Xing MM. Nanomaterials and nanotechnology for skin tissue engineering. Int J Burns Trauma. 2012;2(1):29.

167. Chaudhari AA, Vig K, Baganizi DR, Sahu R, Dixit S, Dennis V, et al. Future prospects for scaffolding methods and biomaterials in skin tissue engineering: a review. Int J Mol Sci. 2016;17(12):1974.

168. Dai C, Shih S, Khachemoune A. Skin substitutes for acute and chronic wound healing: an updated review. J Dermatol Treat. 2020;12:1-10.
169. Kamoun EA, Kenawy E-RS, Chen X. A review on polymeric hydrogel membranes for wound dressing applications: PVA-based hydrogel dressings. J Adv Res. 2017;8(3):217-33.

170. Abazari M, Ghaffari A, Rashidzadeh H, Momeni badeleh S, Maleki Y. Current status and future outlook of nano-based systems for burn wound management. J Biomed Mater Res Part B. 2019

171. Pereira RF, Barrias CC, Bártolo PJ, Granja PL. Cell-instructive pectin hydrogels crosslinked via thiol-norbornene photo-click chemistry for skin tissue engineering. Acta Biomater. 2018:66:282-93.

172. Visser J, Melchels FP, Jeon JE, Van Bussel EM, Kimpton LS, Byrne HM, et al. Reinforcement of hydrogels using three-dimensionally printed microfibres. Nat Commun. 2015;6(1):1-10

173. Yang J, Han C-R, Duan J-F, Xu F, Sun R-C. Mechanical and viscoelastic properties of cellulose nanocrystals reinforced poly (ethylene glycol) nanocomposite hydrogels. ACS Appl Mater Interfaces. 2013;5(8):3199-207.

174. Ahtzaz S, Nasir M, Shahzadi L, Amir W, Anjum A, Arshad R, et al. A study on the effect of zinc oxide and zinc peroxide nanoparticles to enhance angiogenesis-pro-angiogenic grafts for tissue regeneration applications. Mater Des. 2017;132:409-18.

175. Chakraborty S, Ponrasu T, Chandel S, Dixit M, Muthuvijayan V. Reduced graphene oxide-loaded nanocomposite scaffolds for enhancing angiogenesis in tissue engineering applications. R Soc Open Sci. 2018:5(5):172017.

176. LiY, XU T, Tu Z, Dai W, Xue Y, Tang C, et al. Bioactive antibacterial silicabased nanocomposites hydrogel scaffolds with high angiogenesis for promoting diabetic wound healing and skin repair. Theranostics, 2020;10(11):4929-43.

177. Murphy SV, Atala A. 3D bioprinting of tissues and organs. Nat Biotechnol. 2014;32(8):773.

178. Turnbull G, Clarke J, Picard F, Riches P, Jia L, Han F, et al. 3D bioactive composite scaffolds for bone tissue engineering. Bioactive materials. 2018;3(3):278-314.

179. Carrow JK, Kerativitayanan P, Jaiswal MK, Lokhande G, Gaharwar AK. Polymers for bioprinting. Essentials of 3D biofabrication and translation. New York: Elsevier; 2015. p. 229-48.

180. Aljohani W, Ullah MW, Zhang X, Yang G. Bioprinting and its applications in tissue engineering and regenerative medicine. Int J Biol Macromol. 2018;107:261-75.

181. Ng WL, Yeong WY, Naing MW. Development of polyelectrolyte chitosan-gelatin hydrogels for skin bioprinting. Proc CIRP. 2016;49:105-12.

182. Wang S, Lee JM, Yeong WY. Smart hydrogels for 3D bioprinting. Int J Bioprint. 2015;1:1.

183. Vijayavenkataraman S, Lu W, Fuh J. 3D bioprinting of skin: a state-ofthe-art review on modelling, materials, and processes. Biofabrication. 2016;8(3):032001

184. Powell HM, Boyce ST. Engineered human skin fabricated using electrospun collagen-PCL blends: morphogenesis and mechanical properties. Tissue Eng Part A. 2009;15(8):2177-87.

185. Joseph J, Deshmukh K, Tung T, Chidambaram K, Pasha SK. 3D printing technology of polymer composites and hydrogels for artificial skin tissue implementations. Polymer nanocomposites in biomedical engineering: Springer; 2019. p. 205-33.

186. Ren Y, Feng J. Skin-inspired multifunctional luminescent hydrogel containing layered rare-earth hydroxide with 3D printability for human motion sensing. ACS Appl Mater Interfaces. 2020;12(6):6797-805.

187. Sahranavard M, Zamanian A, Ghorbani F, Shahrezaee MH. A critical review on three dimensional-printed chitosan hydrogels for development of tissue engineering. Bioprinting. 2020;17:e00063.

188. Ghezzi CE, Rnjak-Kovacina J, Kaplan DL. Corneal tissue engineering: recent advances and future perspectives. Tissue Eng Part B Rev. 2015;21(3):278-87.

189. Schiffman JD, Schauer CL. A review: electrospinning of biopolymer nanofibers and their applications. Polym Rev. 2008:48(2):317-52.

190. Norouzi M, Boroujeni SM, Omidvarkordshouli N, Soleimani M. Advances in skin regeneration: application of electrospun scaffolds. Adv Healthcare Mater. 2015;4(8):1114-33.

191. Mogoşanu GD, Grumezescu AM. Natural and synthetic polymers for wounds and burns dressing. Int J Pharm. 2014;463(2):127-36. 
192. Mele E. Electrospinning of natural polymers for advanced wound care: towards responsive and adaptive dressings. J Mater Chem B. 2016:4(28):4801-12.

193. Miguel SP, Figueira DR, Simões D, Ribeiro MP, Coutinho P, Ferreira P, et al. Electrospun polymeric nanofibres as wound dressings: a review. Colloids Surf B. 2018;169:60-71.

194. Chen G, Ushida T, Tateishi T. Development of biodegradable porous scaffolds for tissue engineering. Mater Sci Eng, C. 2001;17(1-2):63-9.

195. Chen G, Ushida T, Tateishi T. Scaffold design for tissue engineering. Macromol Biosci. 2002;2(2):67-77.

196. Wang F, Wang M, She Z, Fan K, Xu C, Chu B, et al. Collagen/chitosan based two-compartment and bi-functional dermal scaffolds for skin regeneration. Mater Sci Eng, C. 2015;52:155-62.

197. Chen X, Zhang M, Wang X, Chen Y, Yan Y, Zhang L, et al. Peptide-modified chitosan hydrogels promote skin wound healing by enhancing wound angiogenesis and inhibiting inflammation. Am J Transl Res. 2017;9(5):2352.

198. Lai H-J, Kuan C-H, Wu H-C, Tsai J-C, Chen T-M, Hsieh D-J, et al. Tailored design of electrospun composite nanofibers with staged release of multiple angiogenic growth factors for chronic wound healing. Acta Biomater. 2014;10(10):4156-66.

199. Hadisi Z, Farokhi M, Bakhsheshi-Rad HR, Jahanshahi M, Hasanpour S, Pagan E, et al. Hyaluronic acid (HA)-based silk fibroin/zinc oxide coreshell electrospun dressing for burn wound management. Macromol Biosci. 2020.

200. Xie Z, Paras CB, Weng H, Punnakitikashem P, Su L-C, Vu K, et al. Dual growth factor releasing multi-functional nanofibers for wound healing. Acta Biomater. 2013;9(12):9351-9.

201. Li S, Li L, Guo C, Qin H, Yu X. A promising wound dressing material with excellent cytocompatibility and proangiogenesis action for wound healing: strontium loaded Silk fibroin/Sodium alginate (SF/SA) blend films. Int J Biol Macromol. 2017;104:969-78.

202. Xiong S, Zhang X, Lu P, Wu Y, Wang Q, Sun H, et al. A gelatin-sulfonated silk composite scaffold based on 3D printing technology enhances skin regeneration by stimulating epidermal growth and dermal neovascularization. Sci Rep. 2017;7(1):1-12.
203. Nejaddehbashi F, Hashemitabar M, Bayati V, Abbaspour M, Moghimipour E, Orazizadeh M. Application of polycaprolactone, chitosan, and collagen composite as a nanofibrous mat loaded with silver sulfadiazine and growth factors for wound dressing. Artif Organs. 2019:43(4):413-23.

204. Zahid AA, Ahmed R, ur Rehman SR, Augustine R, Tariq M, Hasan A. Nitric oxide releasing chitosan-poly (vinyl alcohol) hydrogel promotes angiogenesis in chick embryo model. Int J Biol Macromol. 2019;136:901-10.

205. Augustine R, Hasan A, Patan NK, Dalvi YB, Varghese R, Antony A, et al. Cerium oxide nanoparticle incorporated electrospun poly (3-hydroxybutyrate-co-3-hydroxyvalerate) membranes for diabetic wound healing applications. ACS Biomater Sci Eng. 2019.

206. Ababzadeh S, Farzin A, Goodarzi A, Karimi R, Sagharjoghi Farahani M, Eslami Farsani M, et al. High porous electrospun poly ( $\varepsilon$-caprolactone)/ gelatin/MgO scaffolds preseeded with endometrial stem cells promote tissue regeneration in full-thickness skin wounds: An in vivo study. J Biomed Mater Res Part B. 2020.

207. Augustine R, Zahid AA, Hasan A, Wang M, Webster TJ. CTGF loaded electrospun dual porous core-shell membrane for diabetic wound healing. Int J Nanomed. 2019;14:8573-88.

208. Losi P, Briganti E, Errico C, Lisella A, Sanguinetti E, Chiellini F, et al. Fibrin-based scaffold incorporating VEGF-and bFGF-loaded nanoparticles stimulates wound healing in diabetic mice. Acta Biomater. 2013;9(8):7814-21.

209. Shamloo A, Sarmadi M, Aghababaie Z, Vossoughi M. Accelerated fullthickness wound healing via sustained bFGF delivery based on a PVA chitosan/gelatin hydrogel incorporating PCL microspheres. Int J Pharm. 2018;537(1-2):278-89.

\section{Publisher's Note}

Springer Nature remains neutral with regard to jurisdictional claims in published maps and institutional affiliations.
Ready to submit your research? Choose BMC and benefit from:

- fast, convenient online submission

- thorough peer review by experienced researchers in your field

- rapid publication on acceptance

- support for research data, including large and complex data types

- gold Open Access which fosters wider collaboration and increased citations

- maximum visibility for your research: over $100 \mathrm{M}$ website views per year

At BMC, research is always in progress.

Learn more biomedcentral.com/submissions 